\title{
Low-molecular-weight metabolite systems chemistry
}

\author{
Franz Hadacek ${ }^{1 *}$ and Gert Bachmann ${ }^{2}$ \\ 'Plant Biochemistry, Faculty of Biology and Psychology, Albrecht-von-Haller Institut, Georg-August Universität, Göttingen, Germany \\ ${ }^{2}$ Molecular Systems Biology, Ecogenomics and Systems Biology, Faculty of Life Sciences, Universität Wien, Vienna, Austria
}

\section{Edited by:}

Naser A. Anjum, University of Aveiro, Portugal

\section{Reviewed by:}

Naser A. Anjum, University of Aveiro, Portugal

Aryadeep Roychoudhury, St.

Xavier's College, India

Mario Carmelo De Tullio, University

of Bari, Italy

\section{*Correspondence:}

Franz Hadacek, Plant Biochemistry,

Albrecht-von-Haller Institut,

Georg-August Universität,

Justus-von-Liebig-Weg 11,

37077 Göttingen, Germany

e-mail: fhadace@uni-goettingen.de
Low-molecular-weight metabolites (LMWMs) comprise primary or central and a plethora of intermediary or secondary metabolites, all of which are characterized by a molecular weight below 900 Dalton. The latter are especially prominent in sessile higher organisms, such as plants, corals, sponges and fungi, but are produced by all types of microbial organisms too. Common to all of these carbon molecules are oxygen, nitrogen and, to a lesser extent, sulfur, as heteroatoms. The latter can contribute as electron donators or acceptors to cellular redox chemistry and define the potential of the molecule to enter charge-transfer complexes. Furthermore, they allow LMWMs to serve as organic ligands in coordination complexes with various inorganic metals as central atoms. Especially the transition metals $\mathrm{Fe}, \mathrm{Cu}$, and $\mathrm{Mn}$ can catalyze one electron reduction of molecular oxygen, which results in formation of free radical species and reactive follow-up reaction products. As antioxidants LMWMs can scavenge free radicals. Depending on the chemical environment, the same LMWMs can act as pro-oxidants by reducing molecular oxygen. The cellular regulation of redox homeostasis, a balance between oxidation and reduction, is still far from being understood. Charge-transfer and coordination complex formation with metals shapes LMWMs into gel-like matrices in the cytosol. The quasi-polymer structure is lost usually during the isolation procedure. In the gel state, LMWMs possess semiconductor properties. Also proteins and membranes are semiconductors. Together they can represent biotransistor components that can be part of a chemoelectrical signaling system that coordinates systems chemistry by initiating cell differentiation or tissue homeostasis, the activated and the resting cell state, when it is required. This concept is not new and dates back to Albert Szent-Györgyi.

\section{Keywords: primary metabolism, secondary metabolism, redox chemistry, charge-transfer complexes, coordination} complexes, semiconductors, biotransistors, chemoelectrical signaling system

\section{INTRODUCTION}

Low-molecular-weight metabolites (LMWMs) are known to us as nutrients, hormones, vitamins, poisons, chemical weapons, spices, perfume aromas, antioxidants, medicines and biopolymer precursors. The question about their raison d'être, especially for secondary LMWMs, is far from satisfactorily answered (Fraenkel, 1959; Hadacek et al., 2011). From focusing on particular aspects, such as central metabolism and chemical defense, the challenge of gaining insights into LMWM systemic functions increasingly becomes more important. All living organisms can synthetize LMWMs albeit not all accumulate them in amounts that are sufficient enough to stimulate attempts of isolation and structure elucidation. In plants they are especially prominent. Plants have evolved a multitude of storage compartments that range from microscopic glandular hairs to prominent lactifers and resin channels (Gershenzon, 2002; Langenheim, 2003)

The big exploratory era of LMWM structure diversity was in the second half of the former century and mainly carried out by organic chemists and pharmacists. In the last two decades, huge screening programs were started by the pharmaceutical industry to identify new antibiotic and drug candidates and when naturally occurring LMWMs from increasingly exotic and difficult-to-access sources did not suffice, synthetic combinatorial chemistry libraries were added. The problem with many identified candidates is and was: activity is usually accompanied by one or several undesired side effects. Consequently, there exists an undeniable challenge to understand their mode of action.

Surviving in a changing environment successfully represents the major challenge to all living organisms. Whereas high stress from the abiotic and biotic environment kills the organism, low stress levels can cause a priming effect. In attempts to understand this idiosyncratic phenomenon, we should perhaps explore the phenomenon of life from a more chemical perspective. The organic chemist Addy Pross suggested that systems biology actually is systems chemistry (Pross, 2012). Accordingly, Section LMWMs in Living Organisms is providing an overview of LMWM chemical structure diversity and recapitulates their basic reaction chemistry. Section LMWM Coordination Chemistry introduces important aspects of coordination chemistry, which extends the chemical exploration to inorganic chemistry. In Section System Chemistry and Bioelectricity we will attempt to outline bioelectricity as an important physiochemical regulatory component and, based on this, in Section Outlook: LMWMs in 
Chemical Systems Regulated by Electricity propose a concept how LMWMs can contribute to a homeodynamic systems chemistry of living organisms.

\section{LMWMs IN LIVING ORGANISMS DEFINITION, BIOSYNTHESIS, AND ORGANIC CHEMISTRY}

LMWM include all those organic compounds of biological origin with a molecular weight below 900 Dalton (Macielag, 2011). Confusingly, different terminology is used to address them. Pharmaceutical and medicinal researchers call them natural products, or in case of a proven antibacterial activity, antibiotics. Biologists differentiate between primary or central and secondary metabolites, the former being indispensable for growth and development, and the latter essential to survive in the ecosystem. Ecologists call them allelochemicals if they have been identified them as monitoring components of interactions between organisms. Nutritional scientist use the terms antioxidants or nutraceuticals to denote those LMWMS with more or less proven beneficial health effects. Hormones are universal signaling compounds. Vitamins are, by the majority, plant or microbial metabolites that are required by animals for maintaining of their metabolism. Pathologists and food scientists preferentially use the terms bacterial toxins and mycotoxins to point out bacterial and fungal metabolites that can harm human health if occurring in too high concentrations in our food stuffs. Depending on molecular size and the presence and absence of polar functional groups LMWMs are either volatile or non-volatile. There exist numerous review articles and books on LMWMs that focus on one or more of the above mentioned aspects, the cited ones just representing a subjective selection (Betina, 1989; Gräfe, 1992; Seigler, 1998; Reese et al., 2000; Dixon, 2001; Hadacek, 2002; Crozier, 2006; Hedden and Thomas, 2006; Hartmann, 2007; Bednarek and Osbourn, 2009; Buchanan et al., 2009; Greenstein and Wood, 2011; Bräse et al., 2013).

LMWM structural diversity will be illustrated by selected examples in the on-going text (Figures 1-4). One of the basic biosynthetic building blocks to secondary LMWMs is a C2 unit, usually a coenzyme A-bonded acetate. Derivatives from this pathway are called polyketides if ring-shaped, or fatty acids, if open chained. A further biosynthetic building block is a C5 unit, isoprene, that can arise either from the mevalonate pathway or from the later discovered deoxyxylulose phosphate pathway. It represents the precursor to the terpenoids, the second large structural class within secondary LMWMs. Amino acids introduce nitrogen into their structures and the amino acids cysteine and methionine sulfur. Aromatic structures can be formed either by the polyketide or the shikimic acid pathway, the latter also being a prerequisite to synthetize aromatic amino acids. More information is available in the literature (Rohmer, 1999; Romeo et al., 2000; Hadacek, 2002; Buchanan et al., 2009; Weng and Noel, 2012; Anarat-Cappillino and Sattely, 2014).

LWMWs are characterized by different combinations of functional groups, unsaturated bonds and/or heteroatoms. These characteristics define their chemical properties. Two-electron transfers underpin chemical reactions that result in the changing of covalent bonds in a LMWM substrate or product. The chemical textbook structures exclusively show structures with covalent bonds, in which one or more pairs of electrons are shared by two atomic nuclei. In inorganic chemistry, by contrast, ionic bonds prevail that are formed between attracting positively and negatively charged ions, in which one or more electrons from one nucleus are removed and attached to another. Oxidoreductions, the classical redox reactions, in which one molecule, the reductant, becomes oxidized, and the other molecule, the oxidant, reduced, are common. According to molecular orbital (MO) theory, the inherent electron transfer reaction occurs from the highest occupied molecular orbital (HOMO) of the reductant (D, donor) to the lowest unoccupied molecular orbital (LUMO) of the oxidant (A, acceptor). Marcus theory predicts that an electron transfer reaction (1) involves a precursor complex that changes into a successor complex resulting in the formation of radicals, highly reactive molecular species, in which an orbital of one of its atoms is occupied by an unpaired electron (Eberson, 1987; Pross, 1995).

$$
\mathrm{D}+\mathrm{A} \rightarrow[\mathrm{D} \mathrm{A}] \rightarrow\left[\mathrm{D}^{+\bullet} \mathrm{A}^{-\bullet}\right] \rightarrow \mathrm{D}^{+}+\mathrm{A}^{-}
$$

A combination of various factors, (I) strong D-A pairing, (II) steric interactions that decrease the coupling between $\mathrm{D}^{+\bullet}$ and $\mathrm{A}^{-\bullet}$, (III) low $\mathrm{D}^{+}-\mathrm{A}^{-}$bond strength, and (IV) strong delocalization of $\mathrm{D}^{+} \bullet$ and $\mathrm{A}^{-\bullet}$ radical centers, creates a one-electron transfer scenario. Such charge-transfers complexes (2) are characterized more aptly by the configuration mixing model (CFM) (Pross, 1985, 1995; Eberson, 1987).

$$
\mathrm{D}+\mathrm{A} \leftrightarrow\left[\mathrm{D}^{+\bullet}+\mathrm{A}^{-\bullet}+\mathrm{DA}\right]
$$

Charge-transfer complex formation occurs when orbitals of adjacent biomolecules, LMWM and/or proteins, overlap (SzentGyörgyi, 1960, 1968). In protein chemistry, charge-transfer complex formation is viewed as a variant of dipol-dipol interactions. These weak non-covalent bonding forms further include hydrogen bonding, van der Waals forces and hydrophobic interactions. They are generally characterized by locally asymmetric electron distributions (Silverman, 2002). Chargetransfer complexes might also be viewed as a mosaic stone to understand drug-receptor interactions and they are also likely to occur in the gel-like cytosol, the structure of which resembles more a solid than a liquid solution (Doukas, 1975). In attempts to point to potential donor (D) and acceptor (A) atoms that can enter charge-transfer complexes in the illustrated molecule structures, corresponding signatures have been added tentatively into Figures 1-4. The assignments are based either on known redox chemistry or hints from literature (SzentGyörgyi, 1957, 1960; Doukas, 1975). Charge-transfer complexes facilitate electronic mobility and, as a consequence, shortrange metallic conductivity within molecules. Here we take up Albert Szent-Györgyi's suggestion that conjugated $\pi$-electron systems more or less represent electric extension cords because charge-transfer complex formation can induce an electric field (Figures 1-4). More contemporarily, a USB cable would be appropriate. 


\section{PRIMARY OR CENTRAL LMWMs}

Primary or central carbon metabolism converts sugars into a wide range of precursors that generate the entire cell biomass by using the shortest possible enzymatic pathways (Noor et al., 2010). Figure 1 presents exemplary structures of sugars, amino, tricarboxylic (organic), and fatty acids. These metabolites are more or less shared by all extant pro- and eukaryotic organisms with few exceptions; e.g., Archaea possess lipids that are comprised of isoprene chain glycerol ethers instead of fatty acid glycerol esters (De Rosa et al., 1986). Specific combinations of functional element groups in the molecules, alcohols and acids with oxygen, amino groups with nitrogen, and thiol groups with sulfur, occur in the various molecules (Figure 1). By far, the amino acids are the most heterogeneous molecule class. Figure 1 omits nucleobases, which form RNA and DNA.

Central metabolites have been suggested as components of a metabolic chemical system with evolved potential to optimize itself (Pross, 2005, 2012; Shapiro, 2011). Most, tricarboxylic acids being the exception, can serve as building blocks for polymer structures, which not only organize the cell's compartmental structure but also that of tissues of multicellular organisms.

\section{HORMONES AND NEUROTRANSMITTERS}

The illustrated hormones (Figure 2) represent a group of livesustaining metabolites that can regulate the activities of genes, proteins and other cellular metabolites and thus exert major effects on many physiological and ontogenetic processes within and across tissues (Heyland et al., 2005). Hormones, however, are more specific for particular organismic kingdoms. The illustrated derivatives have been chosen not only to exemplify structural diversity but also to illustrate their occurrence in different living organisms. Proteobacteria use acylated homoserine lactones (AHL, 2.1) and Actinobacteria butyrolactones, both fatty acid derivatives, for quorum sensing. Both compound classes were shown to facilitate coordination of metabolic activities within

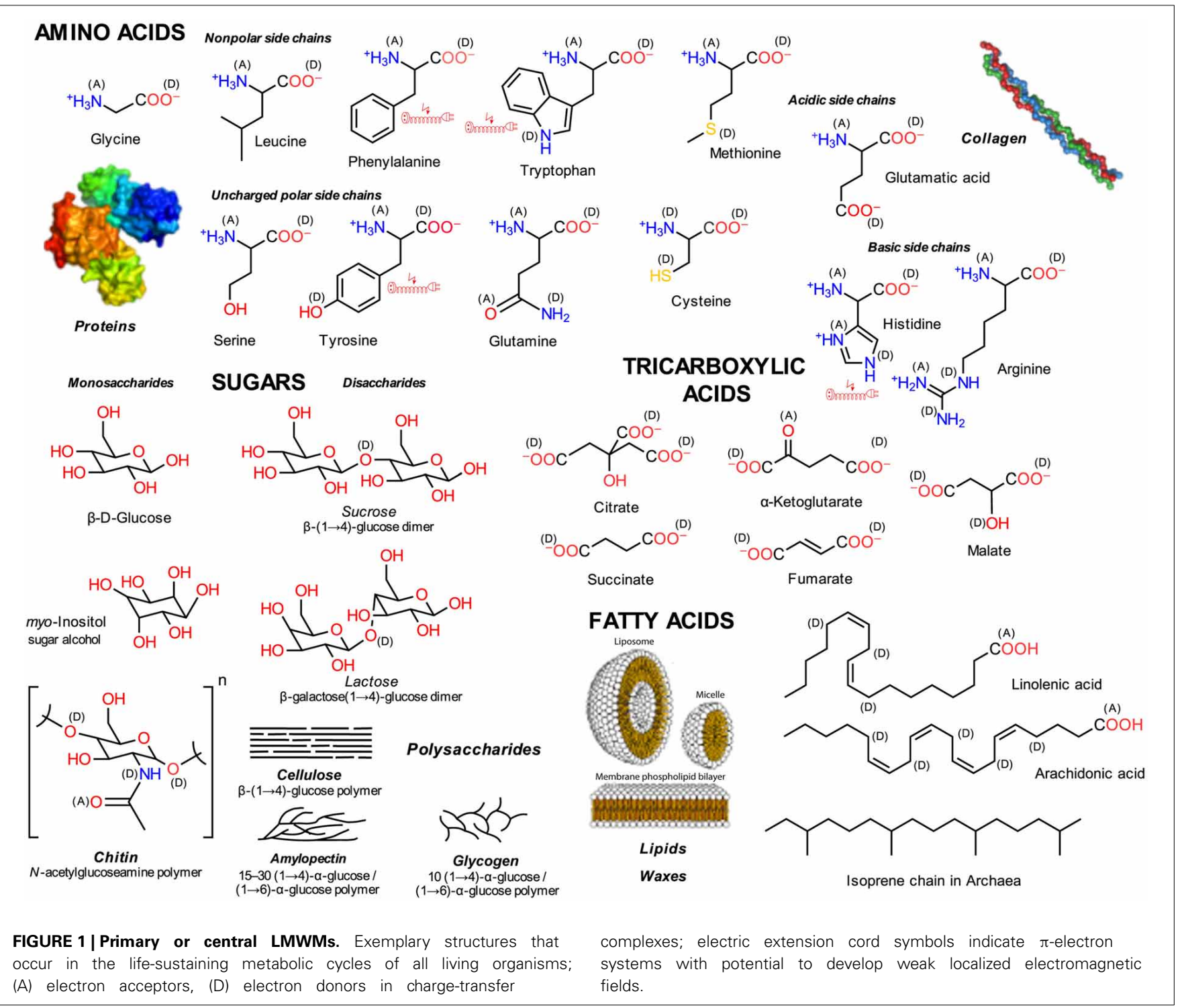




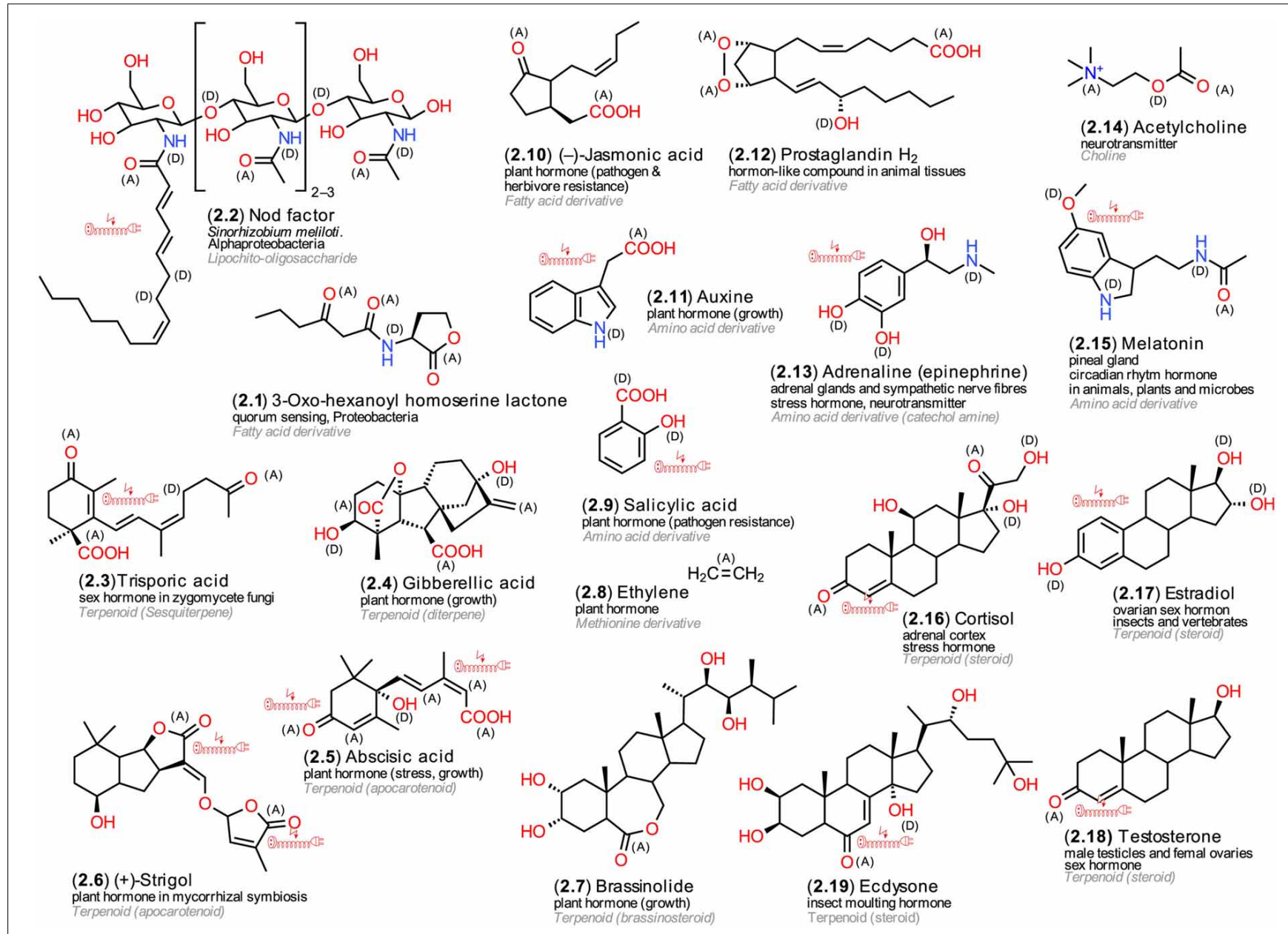

FIGURE 2 | Hormones and neurotransmitters. Exemplary structures from microorganisms, plants and animals; the numbering reflects their appearance in the text, the arrangement follows common biosynthetic pathways; $(A)$ electron acceptors, (D) electron donors in charge-transfer complexes; electric extension cord symbols indicate $\pi$-electron systems with potential to develop weak localized electromagnetic fields. bacterial populations (López-Lara and Geiger, 2010). Rhizobia, but also Alpha- and Beta-proteobacteria, can cause the formation of root nodules in legumes. They use lipo-chitooligosaccharidic nodulation (Nod) factors (2.2). These glycolipids have been identified as initiators of host plant root hair formation and deformation, intra- and extracellular alkalization, membrane potential depolarization, ion flux changes, nodulin gene expression and formation of nodule primordia (D'Haeze and Holsters, 2002). Trisporic acid (2.3) induces spore formation in zygomycete fungi; its mode of action, however, is extracellular similar to that of bacterial acylated homoserine lactones (Gooday, 1978). Interestingly, a prominent plant hormone that stimulates germination, cell differentiation and flowering in plants, gibberellic acid (GA, 2.4), was identified first as a metabolite of the fungus Gibberella fujikuroi (teleomorph Fusarium moniliforme). This fungus utilizes it as a toxin to cause bakanae disease in rice seedlings (Curtis and Cross, 1954; Bartoli et al., 2013). Another structurally strikingly similar plant hormone is abscisic acid (ABA, 2.5), a carotenoid cleavage product (apocarotinoid) that is involved in coordinating responses to various forms of abiotic stress and leaf senescence
(Bartoli et al., 2013). Strigolactones, such as strigol (2.6), another group of apocarotinoids, are believed to be commonly exuded by plant roots. Originally, it was assumed that these compounds facilitate the establishment of parasitic plant haustoria in host tissues, later the discovery of their involvement in facilitating arbuscular mycorrhizal colonization of plant roots provided a more feasible hypothesis for their existence. Recently, also endogenous signaling roles have been suggested (Waldie et al., 2014). Brassinosteroids (2.7) represent a further class of plant growth hormones (Clouse and Sasse, 1998). A volatile plant hormone that can regulate diverse processes is ethylene $(2.8)$ (Bleecker and Kende, 2000). Salicylic acid (2.9), an aromatic amino acid derivative, and jasmonic acid (2.10), a derivative of the unsaturated fatty acid linolenic acid, an oxylipin, represent plant hormones that are involved in resistance against pathogens and herbivores (Fujita et al., 2006). One of the most essential hormones for plant development is the tryptophan derivative auxin (2.11), also known as 3-indol-actic acid (Woodward and Bartel, 2005). The majority of plant hormones have been detected also in green, red, and brown algae (Tarakhovskaya et al., 2007). 
In animals, the term hormones is reserved for metabolites that are produced by highly specialized endocrine tissues and transported by the circulatory system to their distant targets in the body (Jerzmanowski and Archacki, 2013). Among them, three classes resemble LMWM plant hormones, the amino acidderived, the steroid hormones and the eicosanoids. The latter are not synthetized by specific glands and not well soluble in aqueous solutions and therefore fail to fulfill two major classification criterions for animal hormones; as a result they are designated as hormone-like substances in the literature although, in terms of their evolved functionality, they represent hormones. Other animal hormones, polypeptides and small proteins, are outside of the focus of this review. Eicosanoids are derivatives of arachidonic acid, an unsaturated C20 fatty acid, and comprise prostaglandins (2.12) and leukotrienes, both of which are involved in numerous homeostatic functions and inflammation (Funk, 2001). They resemble plant oxylipins, derivatives of the unsaturated C18 fatty acid linolenic acid, and can disturb tissue homeostasis. Epinephrine (adrenaline, 2.13) and norepinephrine (noradrenaline) are tyrosine derivatives that are secreted by the medulla of the adrenal glands. The former modulates cardiovascular and metabolic response to stress, the latter acts more as a neurotransmitter (Greenstein and Wood, 2011). A further neurotransmitter that occurs in many organisms is acetylcholine (2.14) (Preston and Wilson, 2013). The tryptophan derivative melatonin (2.15) is a highly interesting hormone; it can be synthetized by Bacteria, Plants, and Animals and modulates circadian rhythms (Hardeland, 2008). Steroid hormones are also involved in stress regulation; cortisol (2.16) is produced by the adrenal glands and stimulates gluconeogenesis and activates anti-stress and anti-inflammatory pathways (Greenstein and Wood, 2011). Steroid hormones comprise sex hormones, estrogens, such as estradiol (2.17), that regulate menstrual and estrous reproductive cycles, and testosterone (2.18), a hormone that occurs in both sexes but acts differently (Greenstein and Wood, 2011). Another steroid hormone, ecdysone (2.19), regulates insect developmental transitions (Yamanaka et al., 2013). Notably, ecdysones, can also be synthetized in significant amounts by plants (Williams et al., 1989).

A structural comparison of the various hormones reveals similarities and differences. Some of them are efficient electron donators, some strong acceptors, some both. Some possess metal-like conductivity due to $\pi$-electrons, others not. Probably, these different chemical properties not only facilitate diverse interactions with proteins (Doukas, 1975) but may facilitate also crosstalk-like actions between hormones (Pieterse et al., 2009; Spindler et al., 2009).

\section{VITAMINS AND ENZYME COFACTORS}

Biochemical reactions require specific metabolites that provide either energy equivalents or electrons. For plants, the term "supportive metabolites" was suggested (Firn and Jones, 2009). Higher animals cannot synthetize them and thus require them as vitamins. The majority of vitamins are enzyme cofactors or precursors of them (Michal, 1999). Figure 3 exemplifies structures. For example, carotenoids (3.1) represent terpenoid pigments that protect chloroplasts from the reactive oxygen species singlet oxygen that can be formed by energy transfer from relaxing chlorophyll pigments (Ramel et al., 2012). All animals that are endowed with the ability of sight absorb, transport and metabolize carotenoids into retinoids (3.2) (von Lintig, 2012). Tocopherols (3.3) represent further terpenoid antioxidants in the chloroplast and as vitamin $\mathrm{E}$ derivatives protect membrane lipids in animals (Denisov and Denisova, 2009). Phylloquinone (3.4) is an important electron acceptor in photosystem I and, concomitantly, represents an important antioxidant of the vitamin K group for animals (Asensi-Fabado and Munné-Bosch, 2010). An exception to the rule are the vitamin D forms; ergocalciferol is synthetized from ergosterol and cholecalciferol from cholesterol, the former a triterpene alcohol that confers stability to fungal membranes, the latter to animal membranes. Cholecalciferol is a precursor of calcitriol (3.5), which regulates calcium concentrations in the blood (Asensi-Fabado and Munné-Bosch, 2010).

Cobalamine (3.6), vitamin $\mathrm{B}_{12}$, represents one of the largest LMWMs; its porphyrine ring forms a coordination complex (see Section LMWM Coordination Chemistry) with the rare transition metal cobalt as central atom. Besides acting as an important cofactor, cobalamine also possesses notable antioxidant activity. Only Archaea and Bacteria can synthetize it (Michal, 1999; Asensi-Fabado and Munné-Bosch, 2010). Other important vitamins include thiamine (3.7), vitamin $B_{1}$, which is important for oxidative decarboxylation and also can act as antioxidant (Michal, 1999; Jung and Kim, 2003); carboxylation reactions depend on biotin (3.8); pyridoxal phosphate (3.9) is involved in various modifications at the carbon atom 2 of amino acids (Michal, 1999; Ferrier and Harvey, 2014). Ascorbic acid (3.10), also known as vitamin $\mathrm{C}$, confers protection against oxidative stress by acting as antioxidant. Furthermore, ascorbic acid can donate electrons to a wide range of enzymes (De Tullio, 2012). The most common cofactor systems in living organisms that are involved in redox reactions comprise $\mathrm{NAD}^{+} / \mathrm{NADP}$ (mitochondria) (3.11), $\mathrm{NADP}^{+} / \mathrm{NADPH}$ (photosynthesis, pentose phosphate cycle), and FAD/FADH ${ }_{2}$ (oxidative phosphorylation) (3.12). All of them contain the nucleobase adenine as moiety. The former additionally contains nicotine amide, the latter riboflavin. Energy equivalents are provided by ATP (3.13) (Torssell, 1993; Buchanan et al., 2009; Ferrier and Harvey, 2014) that also contains an adenine moiety. The biosynthesis of most cofactors is rather complex and difficult to elucidate due to the low available amounts of these LMWMs (Webb et al., 2007).

Comparing the chemical structures of diverse vitamins (3.1-3.13) with those of hormones (2.1-2.18), the more diverse polarity is notable; 3.1-3.4 are rather unpolar and localized in membranes, 3.5-3.13 are definitely more polar and optimized for a cytosolic environment. The presence of negative charges in the phosphoester moieties specifically enhances affinity to proteins. Apart from the latter, the functional groups are similar to those of the hormones and not as uniform as in some central metabolites, such as sugars and tricarboxylic acids. The numerous donor (D) and acceptor (A) sites provide a basis for forming charge-transfer complexes with proteins. Frequent conjugated unsaturated bonds facilitate the local buildup of electric fields. 


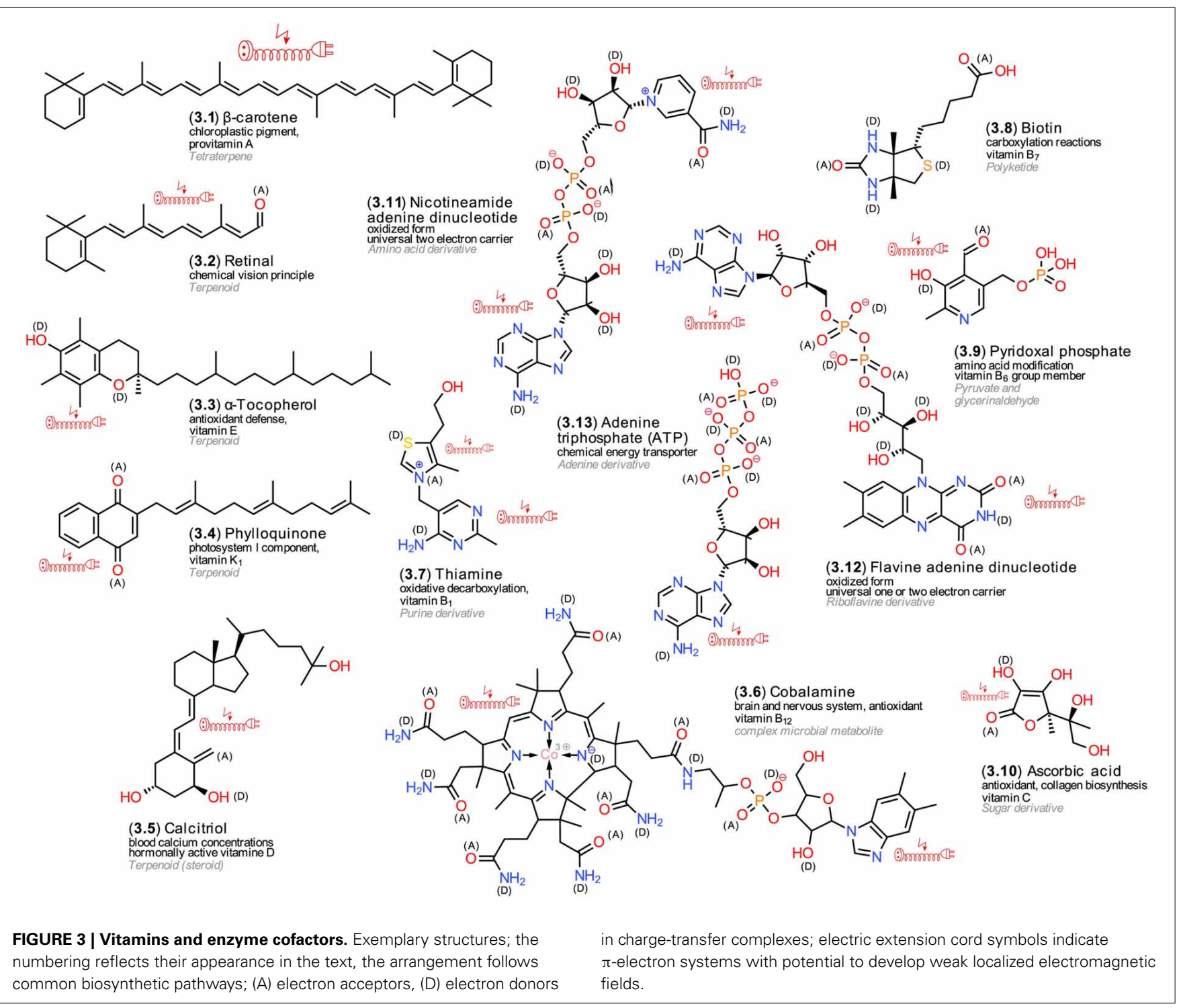

\section{SECONDARY LMWMs}

All LMWM that are deemed dispensable for life-sustaining processes are classified as so-called secondary metabolites, which represent the greatest known LMWM structural diversity by far; their numbers in plants are estimated to exceed 500,000 alone (Mendelsohn and Balick, 1995). Most of them show a highly restricted occurrence, sometimes even limited to a single species. A recently suggested alternative term is "speculative metabolism" (Firn and Jones, 2009). The main difference between Plants and Animals on one hand, and Bacteria and Fungi on the other hand, is that the former accumulate secondary LMWMs in specifically adapted compartments whereas the latter secrete them into their environment (Demain, 1996; Hadacek et al., 2011). Their classifications follows characteristic combinations of biosynthetic building blocks, acetate (C2) or isoprene (C5) units. All organisms, which are capable of synthetizing the aromatic amino acids phenylalanine and tyrosine and possess the enzyme phenylalanine ammonium lyase (PAL), can synthetize cinnamic acid derivatives, the main precursors for aromatic secondary metabolites in photosynthetic Bacteria, Algae and Plants. In heterotrophic organisms, aromatic structures are formed via the polyketide pathway. Combinatorial synthesis that utilizes precursors from various of the mentioned pathways together with variable modification of the base skeletons, which is caused by the low substrate specificity of the involved enzymes, yields the huge structural diversity (Gräfe, 1992; Seigler, 1998; Romeo et al., 2000; Hadacek, 2002; Weng and Noel, 2012). Figure 4 presents an overview of structures that are mentioned in the ongoing text.

To start with, the flavonoid catechin (4.1) and stilbene resveratrol (4.2) represent characteristic phenolic cinnamic acid derivatives from plants that can arise from the shikimic acid pathway (Seigler, 1998; Hadacek, 2002). Both are renowned antioxidant constituents of wine grapes (Burns et al., 2000). Small molecules are volatile and characteristic fragrance components of spices, such as anethole (4.3) in fennel (Shahat et al., 2011). Bacteria 


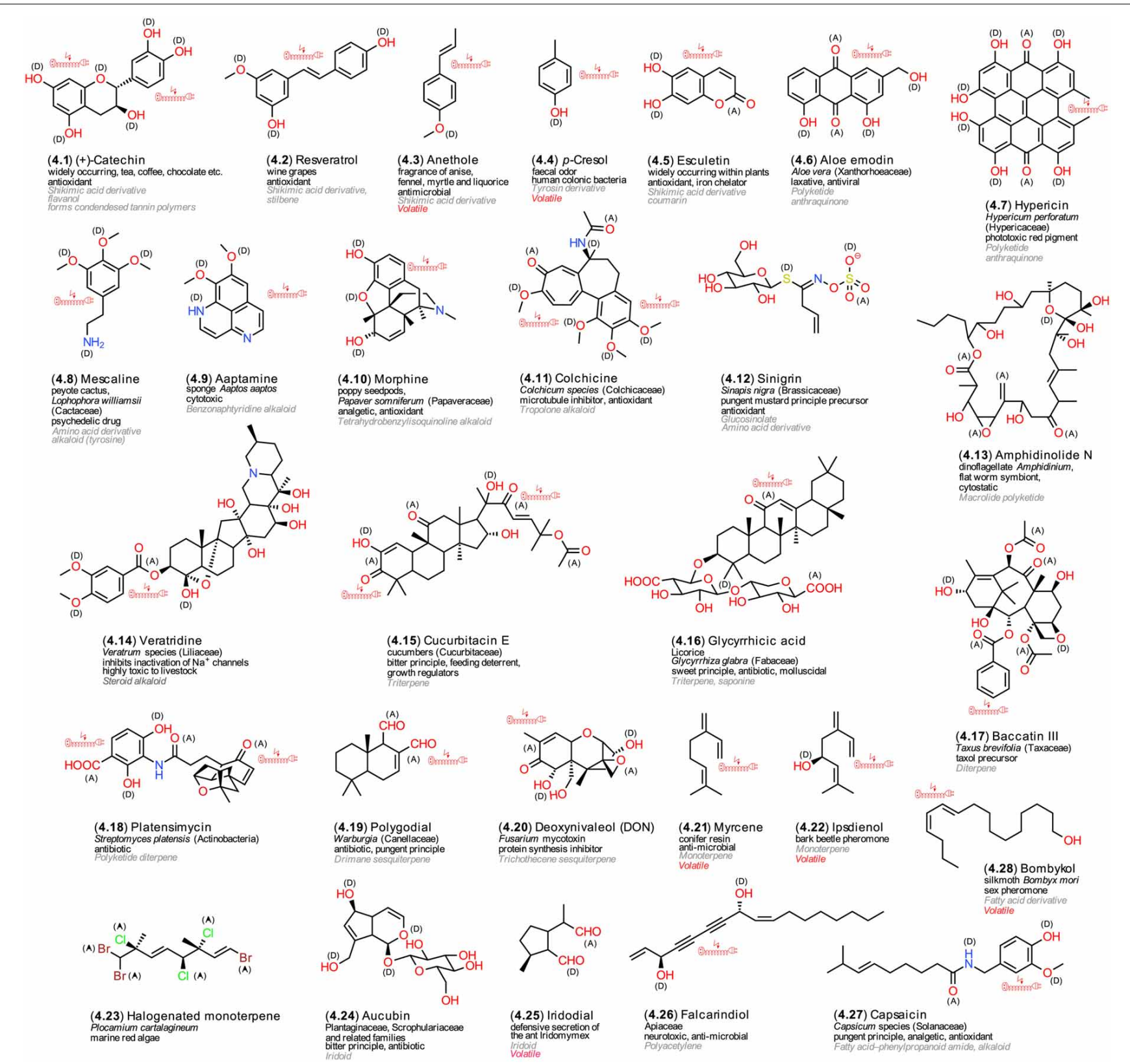

FIGURE 4 | Secondary LMWMs. Exemplary structures from microorganisms, plants, and animals; the numbering reflects their appearance in the text, the arrangement follows common biosynthetic pathways; (A) electron acceptors, (D) electron donors in charge-transfer complexes; electric extension cord symbols indicate $\pi$-electron systems with potential to develop weak localized electromagnetic fields. are also able to produce such volatile metabolites; $p$-cresol (4.4) is responsible for the feces odor and a metabolite of colonic bacteria (Smith and Macfarlane, 1996). Another group of antioxidant phenols are coumarins, e.g., esculetin (4.5) (Hiramoto et al., 1996). Recent studies have pointed out that esculetin and its methoxylated derivative scopoletin can contribute profoundly to iron uptake capabilities of Arabidopsis (Schmid et al., 2014). This points to complex coordination chemistry that combines organic with inorganic chemistry, and which will be discussed later in more detail (Section LMWM Coordination Chemistry). The anthraquinone aloe emodin (4.6) is a polyketide albeit structurally similar to the shikimic acid-pathway derived LMWMs. It possesses both laxative properties and redox chemical activity (Tian and Hua, 2005). Hypericin (4.7) is a dimeric anthraquinone that attracted attention because of its phototoxic effects on grazing animals and, out of context with the former activity, potential usage as antidepressant for humans (Barnes et al., 2001). The tyrosine derivative mescaline (4.8), a metabolite from the peyote cactus, Lophophora williamsii, was used as traditional medicine and hallucinogenic sacrament by North American Indians; recently, a universal redox chemical reaction mechanisms for its effect on the central nervous system has been 
proposed (Kovacic and Somanathan, 2009). A structurally similar compound, aaptamine (4.9) has also been isolated from the sea sponge Aaptos aaptos (Nakamura et al., 1982). Morphine (4.10) is a prominent opioid analgesic drug from the latex of unripe seedpods of the poppy Papaver somniferum. The same compound, however, yielded also positive results in antioxidant assays (Gülçın et al., 2004). Colchicine (4.11) is a tropolone alkaloid that is formed from both phenylalanine and tyrosin; it is known to cause lethal poisoning in humans who mistake meadow saffron leaves for wild garlic, but it also proved to be an efficient antioxidant (Modriansky et al., 2002). The glucosinolate sinigrin (4.12) is a highly water-soluble metabolite that can be converted into thiohydroximate- $O$-sulfate intermediates. Depending on $\mathrm{pH}$, ferrous iron and the presence of myrosinase interacting enzymes, glucosinolates can be converted enzymatically and non-enzymatically into a variety of volatile degradation products, including isothiocyanates and nitriles amongst others, all of which are characteristic for vegetables of the mustard family (Brassicaceae) (Grubb and Abel, 2006). Both the precursor glucosinolates and their volatile degradation products possess antioxidant activity (Cabello-Hurtado et al., 2012). Amphidinolide $\mathrm{N}$ (4.13) is a polyketide that is produced by the flat worm symbiotic dinoflagellate Amphidinium (Ishibashi et al., 1994). The structure shows no aromatic rings and thus resembles more a terpenoid. This compound class provides predominantly aliphatic structures. Terpenoids can, however, still combine with units from other biosynthetic pathways, e.g., the shikimic acid pathway as in veratridine (4.14). This LMWM belongs to a series of highly neurotoxic terpene alkaloids that are synthtized by the Liliaceae s.l. Veratridine and similar compounds efficiently inactivate the regulation of the $\mathrm{Na}^{+}$channels (Greenhill and Grayshan, 1992). Terpenoids are classified on basis of $\mathrm{C} 5$ isoprene unit numbers: Monoterpenes are formed by two, sesquiterpenes by three, diterpenes by four, triterpenes by six and tetraterpenes by eight isoprene units (Seigler, 1998). The latter predominantly comprise chloroplastic pigments with vitamin character (Figure 3). Cucurbitacin E (4.15) and glycyrrhicic acid (4.16) represent two examples with contrasting structures, taste, the former bitter and the latter sweet (Seigler, 1998). One of the most prominent of all diterpene derivatives is taxol, which has gained a reputation in breast cancer chemotherapy; its diterpene precursor, baccatin III (4.17), occurs in the stem bark of the American yew tree Taxus brevifolia (Wall and Wani, 1995). Bacteria also can synthetize diterpene derivatives; the recently discovered antibiotic platenmycin (4.18) represents a notable example (Wang et al., 2006). Drimane sesquiterpenes, such as polygodial (4.19), show a restricted occurrence in a few rather unrelated lower and higher plants. Some fungi, however, are also able to synthetize drimane sesquiterpenes (Jansen and de Groot, 2004). If fungal metabolites accumulate in our foods stuffs, especially in the cereal crops maize and wheat, they are designated as mycotoxins. Among the most prominent and deleterious of them we find trichothecene sesquiterpenes. An often mentioned compound is deoxynivaleol (DON, 4.20), which affects the functioning of ribosomes (ribotoxic stress response) and can cause oxidative stress (Wu et al., 2014). Monoterpenes, in addition to phenylpropenes, represent the major plant odor components; derivatives such as myrcene (4.21) occur in especially large amounts in conifer resin. Bark beetles attacking these trees, in some years with devastating consequences, can utilize monoterpenes that are thought to constitute some kind of chemical defense against them as precursors for pheromones, such as ipsdienol (4.22). These volatile compounds help bark beetles to coordinate their behavior; some species have been found to be capable of synthetize these monoterpenes even by themselves (Seybold et al., 2006). Monoterpens, as all other terpenoid types, can be produced by many different organisms; for example, marine red algae synthetize heavily halogenated derivatives (4.23) (Fusetani, 2012). Iridoids, such as aucubin (4.24), are irregular monoterpenes and thus not easily recognizable as terpenoids. They occur in the plant families Plantaginaceae, Scrophulariaceae, and Gentianaceae, where they contribute to rapid browning during the drying process and bitter taste; they are, however, also produced by insects, e.g. iridodial (4.25) by the ant Iridomyrmex (Seigler, 1998). Finally, fatty acids also can act as precursors for secondary metabolites. Polyactylenes have similar chain-like structures with a high proportion of unsaturated double and often also triple bonds albeit without nitrogen. Falcarindiol (4.26) and related structures have been identified as neurotoxins and antifungals (Christensen and Brandt, 2006).The fatty acid amide capsaicin (4.27) is the pungent principle of red chili, but was also shown to be an antioxidant (Srinivasan, 2014). Volatiles fatty acid derivatives play an important role as intraspecific insect pheromones by facilitating the location of females by males. The first one elucidated was bombykol (4.28) that is produced by the domesticated silk moth Bombyx mori. Males possess two receptors in adjacent pheromone-sensitive neurons in their antennae, one for bombykol and another, interestingly, for its oxidized form, bombykal (Nakagawa et al., 2005).

The presented secondary LMWM examples illustrate the difficulty of assigning specific structures to specific organisms and specific biological activities to specific structures. One of the more important factors that determines LMWM beneficial and toxic effects is their concentration. Often the same compound can exert beneficial effects in low concentration and toxic in higher, a phenomenon that is known as hormesis (Calabrese, 2005). Generally, organic compounds are not well soluble in aqueous solutions. However, the cytosol is not an aqueous solution but has a mysterious gel-like structure (Pollack, 2001). Its mystery is caused also by its in accessibility to standard analytical methods due to the colloidal matrix structure that is formed by LMWMs and proteins. For certain, strong electron acceptor and donor properties contribute to biological activity, but not all strong electron acceptors are necessarily pro-oxidant toxins and not all strong electron donators antioxidants or hormones. Aromaticity is often connected with biological activity, but not exclusively so. Basically, in terms of functional groups, aromaticity, electron donor and acceptor capabilities, a comparison of hormones, most vitamins and secondary LMWM does not reveal any fundamental differences. Solubility and the potential of forming charge-transfer complexes with protein functional groups may constitute essential factors that affect their biological activity, but not exclusively so. 


\section{LMWM STRUCTURE-ACTIVITY CONSIDERATIONS}

Comparing the structures of different LMWMs in Figures 1-4, it becomes apparent that only the different types of primary, basic, or central metabolites, such as amino acids, organic acids, sugars and fatty acids, are characterized by specific combinations of unsaturated bonds and heteroatoms. Others, hormones, vitamins, and secondary LMWMs lack this characteristic. In evolving as components of the general metabolic pathways, central LMWM structures most probably oblige to the specific chemistry that is required of them to contribute accordingly to the metabolic pathways of which they have evolved to be a part of (Bar-Even et al., 2012). Starting from partially enzymatic or nonenzymatic reaction cascades, gene and operon duplication events and gene elongation contributed fundamentally to the evolution of a set of specific enzymes that controls the chemistry of the extant metabolic pathways (Fani and Fondi, 2009).

Other LMWM groups, hormones, vitamins, and coenzymes and secondary LMWMs, however, do not share comparable structural characteristics, similarly as their distribution is not as widespread as that of central metabolites. Their currently attributed functions are also not as clear-cut. For example, several nitrogen-containing secondary LMWM can interact with major neuroreceptors, such as cholinergic, adrenergic, serotonergic and GABAergic neuroreceptors (GABA, $\gamma$-aminobutyric acid), and $\mathrm{Na}^{+}, \mathrm{K}^{+}, \mathrm{Cl}^{-}$, and $\mathrm{Ca}^{+}$-channels. This explains why the intake of larger dosages inevitably causes substantial physiological and psychological disturbances (Wink and van Wyk, 2008). In the past, conversely, certain nitrogen-containing LMWMs were regarded just to serve as simple nitrogen storage intermediaries (Rosenthal, 1982). The currently must broadly accepted concept posits that the major cellular targets of LMWMs are proteins, specifically the three-dimensional structure of proteins, including receptors, enzymes, ion channels, transporters, hormones, transcription factors, regulatory and cytoskeletal proteins. Membrane fluidity and permeability represents a further target area and, last but not least, LMWMs can react directly with both DNA and RNA (Wink and Schimmer, 2010). Non-covalent complex formation, especially that of the charge-transfer type, may contribute as an important mosaic stone to the required specificity of LMWMs (Szent-Györgyi, 1960, 1968; Doukas, 1975). But to obtain more detailed insights into LMWM chemistry, we have to consider oxygen and coordination chemistry, both of which form the boundary between organic and inorganic chemistry.

\section{LMWM COORDINATION CHEMISTRY CHEMISTRY OF LIFE}

Predominantly, LMWM chemistry is viewed as organic chemistry. In this section, the focus, however, is set on selected inorganic elements, whose changing availability and adopted utilization has shaped the evolution of living organisms besides organic chemistry. Life started with anaerobic prokaryotes, in which the earliest organic chemistry formed DNA itself in a reductive milieu that required hydrogen input from water. As a result, about 3 billion years (bya) ago, the environment changed to more oxidized conditions. These processes are thought to have facilitated the development of protection mechanisms against oxygen and, subsequently, the development of aerobic prokaryotes. The second most important chemical change in evolution was the appearance of eukaryotic cells, which is assumed to be facilitated by a sequence of events that led to a systematic development of the combined inorganic/organic chemistry in attempts to separate the unavoidable oxidative from the reductive chemistry. Among novel structures we find membranes, the capture of bacteria as organelles (chloroplasts and mitochondria) and the calcium messenger system. During the period of two to one bya less changes occurred. Shortly after one bya, oxygen concentration began rising again leading to unavoidable changes in the environmental chemistry. In parallel, the cellular oxidative chemistry evolved to produce multicellular eukaryotes, the third very important chemical change. Protecting the cellular reductive chemistry from the increasingly diverse oxidative chemistry outside of the cell increased the demand for developing additional compartments, the realization of which was only possible in multicellular eukaryotes. Oxidative extracellular and vesicle chemistry led to crosslinking of connective structures by restricting their movement and creating organs of differentiated cells. Especially copper enzymes helped connective tissues to grow and in the synthesis of many LMWM messengers that facilitated communication between cells and organs. Concomitantly, hydrolytic zinc proteins managed cleavage of these tissues. The same element proved essential in the development of zinc finger transcription factors that help relating hormone information to gene expression. Connective tissues and messengers for the control of the whole organism with outer skin layers enabled the evolution of huge plants and animals. The latter developed fast $\mathrm{Na}^{+} / \mathrm{K}^{+}$ exchange currents in nerves, which resulted in the evolution of brains. Both the nerves and the brain utilize the potential of $\mathrm{Na}^{+} / \mathrm{K}^{+}$gradients that have been developed by the earliest cells by excluding $\mathrm{Na}^{+}$. Brain development enabled man finally to understand the chemistry and physics behind it. Between 600 and 400 million years ago (mya), oxygen levels ceased to rise and environmental changes decreased, which implies that no cellular chemical changes occurred from this time point onward and only mutations could change DNA to produce species variants. This topic is covered in much detail by two excellent books (Williams and Fraústo da Silva, 2006; Williams and Rickaby, 2012).

\section{OXYGEN AND OTHER REACTIVE SPECIES}

Today's oxygen-rich atmosphere makes oxidative stress unavoidable. Aerobic metabolism and the exposure to various forms of abiotic and biotic stress creates the so-called "Oxygen Paradox." On the one hand, aerobic life's energy supply depends on the reduction of molecular oxygen, on the other hand, oxygen is toxic to life in higher concentrations (Davies, 2000). In tissues, therefore, oxygen concentration usually rises only to one fifth of that which is found in ambient air. One factor that makes oxygen dangerous is its incomplete reduction by accidental oneelectron transfers, which do not yield water but various reactive oxygen species (ROS). These include superoxide anion radical $\left(\mathrm{O}_{2}^{\bullet-}\right)$, hydrogen peroxide $\left(\mathrm{H}_{2} \mathrm{O}_{2}\right)$ and hydroxyl radical $(\bullet \mathrm{OH})$ (Figure 5) (Demidchik, 2015). Another reactive oxygen species is singlet oxygen $\left({ }^{1} \mathrm{O}_{2}\right)$, a dangerous byproduct of photosynthesis in plants. Insufficient energy dissipation results in the formation of an excited triplet state chlorophyll that can transfer its energy on 




FIGURE 5 | Redox and coordination chemistry of LMWMs. Reactive species chemistry is marked in red and coordination chemistry in blue (exception bar graph); subtitles explain the details; chl, chlorophyll; ${ }^{n}$, variable oxidation states.

ground-state oxygen $\left({ }^{3} \mathrm{O}_{2}\right)$ (Triantaphylidès and Havaux, 2009). In attempts of keeping the threat of the high ROS reactivity at minimum, various LMWM antioxidants and enzymes have evolved (Fridovich, 1998; Apel and Hirt, 2004; Halliwell and Gutteridge, 2007).

Besides reactive oxygen species, we also know reactive nitrogen species (RNS), for example nitric oxide $(\bullet \mathrm{NO})$, and sulfur reactive species, for example thiols, disulfides, sulfenic acid derivatives, thio-sulfinates and -sulfonates, and thiyl radicals, the latter presently being less in the research focus compared to RNS (Giles and Jacob, 2002; Gruhlke and Slusarenko, 2012; Groß et al., 2013). The radical ${ }^{\bullet} \mathrm{NO}$ can arise by the following routes: (I) by compartment-specific reactions; (II) in chloroplasts and plant mitochondria from nitrite $\left(\mathrm{NO}_{2}\right)$ reduction by electron transport chain deficient processes (accidental one-electron transfers); (III) in plant peroxisomes from nitrite reduction by xanthine oxidoreductase; (IV) in the plant cytoplasm by nitrite reduction; (V) in the plant apoplast spontaneously at low $\mathrm{pH}$ by membrane-bound nitrite and nitrate reductases; and (VI) in mammalian cells nitric oxide synthase (NOS, Figure 5) oxidizes the amino acid arginine. The latter enzyme has not yet been identified in plants although being suspected to be involved in most of its formation processes. Nitric oxide can be highly toxic because it can more or less react with ROS, for example with peroxynitrite (Figure 5) and also every pro-and antioxidant LMWM (Groß et al., 2013). Furthermore, proteome wide-scale analyses revealed that nitric oxide can nitrosylate sulfur groups besides of cysteine in proteins, which has a fundamental effect on their functions (Astier et al., 2012).

Complex formation, short half-lives and high reactivity characterize the various reactive species of oxygen, nitrogen and sulfur. This supports increasingly the notion that reactive oxygen and nitrogen species signaling, antioxidants and thioredoxin mediated redox regulation just represent parts of the more or less same broad concept. The integration of different redox inputs could represent a system that regulates proteolysis, gene expression and functioning of specific metabolic pathways in a more graded fashion and functions independently of a binary "yes or no" response (De Tullio, 2010). Figure 5 presents a summary of the various oxygen, nitrogen and sulfur reactive species, and chemical reactions involved in their formation. The various radicals can readily react with each other, as well as with LMWMs, proteins and membranes in the cell (Giles and Jacob, 2002; Halliwell, 2006; Møller et al., 2007; Groß et al., 2013). The ability of some 
LMWMs to reduce molecular oxygen by one-electron transfers is regarded as the major mechanism contributing to their cytotoxicity (Kappus and Sies, 1981). This pro-oxidant mode of action is utilized by nearly all efficient anti-cancer drugs (Watson, 2013).

\section{BIOINORGANIC OR COORDINATION CHEMISTRY OF LMWM}

LMWM contain more or less the same elements as proteins. They can be divided in non-metals and metals. The latter differ from the former in their ability of conducting electricity in the condensed state. Among non-metals we typically find $\mathrm{C}, \mathrm{N}$, $\mathrm{O}, \mathrm{S}, \mathrm{P}, \mathrm{Cl}$, as well as $\mathrm{H}$, but also $\mathrm{B}$ and Se. The fact that metals of the first two periods possess less than three electrons in their outer scale contributes significantly to their ability to form cations $\left(\mathrm{M}^{\mathrm{n}+}\right)$. This is especially easy for metals of the groups 1 , $2,3,12$, and 13 , among which we find $\mathrm{Na}, \mathrm{Mg}, \mathrm{Al}, \mathrm{K}$, and $\mathrm{Ca}$. Transition metals from the groups 4-11, however, are less prone to behave like this. Fe, the most common transition metal in the Earth's crust, $\mathrm{Mn}, \mathrm{Cu}, \mathrm{Zn}, \mathrm{V}$, and in sea water additionally $\mathrm{Co}, \mathrm{Ni}$, and Mo, are among the most abundant and/or available (Fraústo da Silva and Williams, 2001; Williams and Fraústo da Silva, 2006; Crichton, 2008; Ochiai, 2008; Marschner, 2012). Table 1 presents a compact summary of known biochemical functions of the various elements. Metals can serve as essential catalysts, either in acid/base and/or in electron transfer reactions. Those metals that lack good cation formation properties depend on forming coordination complexes with either organic or inorganic ligands (Figure 5). The metal central atom is a Lewis acid and the organic or inorganic ligand a Lewis base. In terms of bond strength, the coordination bond resembles a covalent bond but stability decreases with low $\mathrm{pH}$. Coordination complexes can be of tetrahedral, trigonal, linear, trigonal bipyramid, or octahedral geometry, which means that one central atom can coordinate various ligands. Depending on the nature of the ligand and the stereochemistry of the central atom the standard redox potentials of $\mathrm{Cu}^{\mathrm{II}} / \mathrm{Cu}, \mathrm{Fe}^{\mathrm{III}} / \mathrm{Fe}^{\mathrm{II}}, \mathrm{Mn}^{\mathrm{II}} / \mathrm{Mn}^{\mathrm{II}}, \mathrm{Co}^{\mathrm{II}} / \mathrm{Co}^{\mathrm{II}}$ can be altered by more than $1.0 \mathrm{~V}$ (Crichton, 2008).

Generally we know LMWMs as simple, uncoordinated compounds because in attempts to isolate them from their sources the complexes are usually destroyed. Nearly all LMWMs with oxygen, nitrogen and sulfur can act as Lewis bases and thus participate as ligands in coordination chemistry. Depending on their actual state as uncoordinated molecule or ligand in a coordination complex, LMWMs can act as catalysts. Figure 5 presents an example: Hydroxyl radicals are among the most aggressive reactive oxygen species with the exclusive ability to trigger chain oxidations on nearly every biomolecule (Voeikov, 2001; Halliwell and Gutteridge, 2007; Demidchik, 2015). The deoxyribose degradation assay allows assessment of their iron-catalyzed formation rate from hydrogen peroxide by quantification of deoxyribose oxidation products as thiobarbituric acid-reactive species. The naphthoquinone juglone, an allegedly allelopathic secondary LMWM of the walnut tree, can form coordination complexes

Table 1 | Main biochemical functions of elements (Fraústo da Silva and Williams, 2001; Crichton, 2008; Marschner, 2012; Williams and Rickaby, 2012).

\begin{tabular}{|c|c|c|c|c|}
\hline General & Elements & Chemical form & Uptake & Specific functions (examples) \\
\hline \multicolumn{5}{|l|}{ NON-METALS } \\
\hline \multirow[t]{2}{*}{$\begin{array}{l}\text { Major cell constituents, } \\
\text { LMWMs and proteins }\end{array}$} & $\begin{array}{l}\mathrm{C}, \mathrm{H}, \mathrm{O}, \mathrm{N}, \mathrm{S} \\
(\mathrm{Se})\end{array}$ & $\begin{array}{l}\text { Lipo- and hydrophylic } \\
\text { molecules }\end{array}$ & $\begin{array}{l}\mathrm{CO} 2, \mathrm{HCO}^{-}, \mathrm{H}_{2} \mathrm{O}, \mathrm{O} 2 \\
\mathrm{NO}^{-}, \mathrm{SO}^{2-}, \mathrm{SO} 2\left(\mathrm{SeO}^{2-}{ }^{2-}\right)\end{array}$ & $\begin{array}{l}\text { Essential elements involved in } \\
\text { enzymatic reactions, low- and } \\
\text { high-molecular-weight metabolites, } \\
\text { polymers }\end{array}$ \\
\hline & $P$ & Phosphate esters & Phosphates & Energy transfer \\
\hline \multirow[t]{2}{*}{ Amorphous hard structures } & $\mathrm{B}$ & $\begin{array}{l}\text { Esters with polyhydroxy } \\
\text { compounds }\end{array}$ & Boric acid & $\begin{array}{l}\text { Cell wall component, essential for } \\
\text { plants but not animals }\end{array}$ \\
\hline & $\mathrm{Si}$ & Coordination complex & Silicic acid & $\begin{array}{l}\text { Major element in plants, minor in } \\
\text { animals (shells of lower animals) }\end{array}$ \\
\hline Non-specific & $\mathrm{Cl}$ & Anion & $\mathrm{Cl}^{-}$ & Ionic messenger, ion balance \\
\hline \multicolumn{5}{|l|}{ METALS } \\
\hline Structural & $\mathrm{Ca}, \mathrm{Mg}$ & $\begin{array}{l}\text { Sparingly soluble } \\
\text { inorganic compounds }\end{array}$ & As ions & $\begin{array}{l}\text { Skeleton, shells, teeth, } \\
\text { membranes, muscles }\end{array}$ \\
\hline Electrochemistry & $\mathrm{K}, \mathrm{Na}(\mathrm{Ca}, \mathrm{Mg})$ & Free cations & As ions & $\begin{array}{l}\text { Nerves, metabolic energy } \\
\text { Electrolytic equilibria and currents }\end{array}$ \\
\hline Acid-base catalysis & $\mathrm{Zn}(\mathrm{Ni}, \mathrm{Mn})$ & Coordination complex & $\begin{array}{l}\text { Predominantly as } \\
\text { coordination complex }\end{array}$ & $\begin{array}{l}\text { Food digestion (Zn), Urea hydrolysis } \\
\text { (Ni) Water splitting (Mn) }\end{array}$ \\
\hline Redox catalysis & $\begin{array}{l}\mathrm{Fe}, \mathrm{Cu}, \mathrm{Mn} \\
\mathrm{Mo},(\mathrm{Co}, \mathrm{Ni}, \mathrm{V})\end{array}$ & Coordination complex & $\begin{array}{l}\text { Predominantly as } \\
\text { coordination complex }\end{array}$ & $\begin{array}{l}\text { Oxygen reaction (Fe, } \mathrm{Cu}, \mathrm{Mn} \text { ), } \\
\text { Oxygen production (Mn), Oxidation } \\
\text { outside cytoplasm (Cu), Nitrogen } \\
\text { fixation (Mo), Nucleotide reduction } \\
\text { (Co) }\end{array}$ \\
\hline Signaling to DNA & $\begin{array}{l}\mathrm{Ca}, \mathrm{Cu}, \mathrm{Fe} \\
\mathrm{Mg}, \mathrm{Zn}\end{array}$ & Coordination complex & $\begin{array}{l}\text { Ca as ion; all others as } \\
\text { coordination complexes }\end{array}$ & Binding to transcription factors $(\mathrm{Zn})$ \\
\hline Various specific functions & $\begin{array}{l}\mathrm{Mg} \\
\mathrm{Fe}, \mathrm{Cu}\end{array}$ & $\begin{array}{l}\text { Coordination complex } \\
\text { Oxygen transport }\end{array}$ & $\begin{array}{l}\text { Ion, } \\
\text { Coordination complex }\end{array}$ & $\begin{array}{l}\text { Chlorophyll, phosphate metabolism } \\
\text { Proteins }\end{array}$ \\
\hline
\end{tabular}


with Fe ions only if iron is not complexed by EDTA. If iron is added as EDTA complex to the reaction mixture, juglone remains a free molecule. Figure 5 illustrates the dramatic difference between the two scenarios in terms of hydroxyl radical formation (Fenton chemistry) catalysis (Chobot and Hadacek, 2009). The only difference is the presence and absence of EDTA, ascorbic acid is present in identical amounts in all tested concentrations of the two setups. The results from this experiment provide us with a faint idea of the difficile effects ligand identity can exert on metal catalysts. Even in haem iron (Figure 5), still two coordination sites remain free to catalytic activity-modifying ligands.

\section{ROS CHEMISTRY IN WATER}

One puzzling fact is that half-lives of ROS are assumed to be extremely short in the cytosol, for ${ }^{1} \mathrm{O}_{2} 1 \mu \mathrm{s}, \mathrm{O}_{2}^{\bullet-} 1 \mu \mathrm{s}, \mathrm{H}_{2} \mathrm{O}_{2}$ $1 \mathrm{~ms}$, and ${ }^{\bullet} \mathrm{OH} 1 \mathrm{~ns}$ (Møller et al., 2007). The notion about the potential role of ROS has changed in the last decades. What was originally considered a toxic byproduct is now seen as essential component of cellular information signaling, especially in case of $\mathrm{H}_{2} \mathrm{O}_{2}$. In this context, the mechanism how ROS may be efficiently involved in long distance signaling is still under debate. A recent study summarized the problems: whilst $\mathrm{H}_{2} \mathrm{O}_{2}$ signaling based on pure diffusion without relaying stations is theoretically possible, the experimentally observed cellular background $\mathrm{H}_{2} \mathrm{O}_{2}$ concentrations are too high and enzymatic degradation too slow (Vestergaard et al., 2012). If catalytic formation, enzymatic or non-enzymatic, does not correspond to the observed $\mathrm{H}_{2} \mathrm{O}_{2}$ concentrations, the question about their source still remains unanswered.

Research on water has a turbulent history (Pollack, 2013). Actually, the idea that water gets more structured near the freezing point is not a new one (Szent-Györgyi, 1957), and several authors have suggested that this happens to water in the vicinity of hydrophilic and charged surfaces (Ling, 2001; Pollack, 2013). This proposed concept is not generally accepted (Ball, 2008), but the simple experiment that fluorescent dyes change the quality of their emitted light in liquid and freezing water provides us with some food for thought (Szent-Györgyi, 1957). It also creates a novel scenario for ROS (Figure 5). Vladimir Voeikov proposes that the formation of reactive oxygen species is more likely to occur in a structured water environment; experimental evidence is provided by ultraweak photon emission studies (Hercules, 1969; Voeikov, 2001, 2006). The possible proposed reactions include the hydrolytic cleavage of a water molecule in hydroxyl and hydrogen radical and the oxidation (burning) of water by molecular oxygen that is entering the aqueous solution by diffusion (Figure 5). Furthermore, these reactions are assumed to occur perpetually in an oscillatory mode. One tempting aspect of this proposed concept is that LMWMs can affect the speed of these reactions and thus not only change the intensity but also the frequency of the oscillation (Voeikov, 2001, 2006).

\section{SYSTEM CHEMISTRY AND BIOELECTRICITY SYSTEMS BIOLOGY OR SYSTEMS CHEMISTRY}

During the last decade the term systems biology became more and more prominent. The goals of this emerging field are best described by Denis Noble, one of its pioneers: "Systems biology ... is about putting together rather than taking apart, integration rather than reduction. It requires that we develop ways of thinking about integration that are as rigorous as our reductionist programs, but different ... It means changing our philosophy, in the full sense of the term" (Noble, 2006). Undoubtedly, our view on LMWMs would also benefit from such an approach. In Section LMWM Coordination Chemistry we have provided an overview in terms of which chemistry LMWMs can cause. It can happen already on the pre-receptor level; steroid hormones represent an example (Mindnich et al., 2004). Most likely, LMWMs represent an important system component besides proteins and DNA.

In recent years, another new field, systems chemistry has taken shape (Kindermann et al., 2005). It is aimed at understanding the chemical origins of biological organization (Ruiz-Mirazo et al., 2014). As a consequence, Addy Pross suggested to incorporate Darwinian biological theory as replicative chemistry into a more general chemical theory of matter (Pross, 2012). Any chemical system, however, that is part of a biological system requires coordination mechanisms, some kind of cooperativeness. How this cooperativeness can work is perfectly outlined in Albert Szent-Györgyi's book "Bioenergetics": Chemical structures are comprised of letters and dashes, and biochemistry, following chemistry, has excelled similarly in describing structures and reactions by letter-dash-letter symbols (Figures 1-5). Quantum physics turned atoms into probability densities of electrons that build molecules of fantastic and changing shape. Accordingly, biological phenomena represent subtle changes in the shape that take place in dimensions still unknown to classical chemistry. One problem for quantum physics is that models with more than two electrons create unsurmountable mathematical difficulties. Classical biochemistry assumes that no interaction can take place between two molecules without touching one another but- as Szent-Györgyi points out-manifold interactions can take place through energy bands and the electromagnetic fields, which occur in water and its structure as the matrix of biological reactions (Szent-Györgyi, 1957).

\section{BIOELECTRICITY}

At the end of the 18th century electrical phenomena in plants became known a couple of years earlier than in animals, but studies in the former have been eclipsed by those of neurons until recently (Niklas and Spatz, 2012). Electroneutrality requires equal numbers of anions and cations, and even if they differ slightly, an electric potential difference $\Delta \Psi$ develops. In cells with an approximate radius of $30 \mu \mathrm{m}, \Delta \Psi$ of membranes lies in the $100 \mathrm{mV}$ range. Cell membranes are semipermeable. In aqueous solutions, all electrically charged molecules exist in form of hydrated ions, and because of the differences in charge and size, their hydration spheres, exclusion zones, they differ in volume. Semipermeable membranes are assumed to use dialysis to restrict the permeability according to the hydrated ion size. A permeation equilibrium constitutes as a result of the osmotic pressure and the electric field potential (Figure 6A). Ions that fail permeating a membrane start accumulating on one side of the membrane and accordingly build up an electric charge (Diamond and Wright, 1969; Hille, 2001; Niklas and Spatz, 2012). The resting $\Delta \Psi$ between the interior and exterior of a biological cell is -40 to $-80 \mathrm{mV}$. If $\Delta \Psi$ is shifted 
A Biocapacitor $\dashv \vdash$

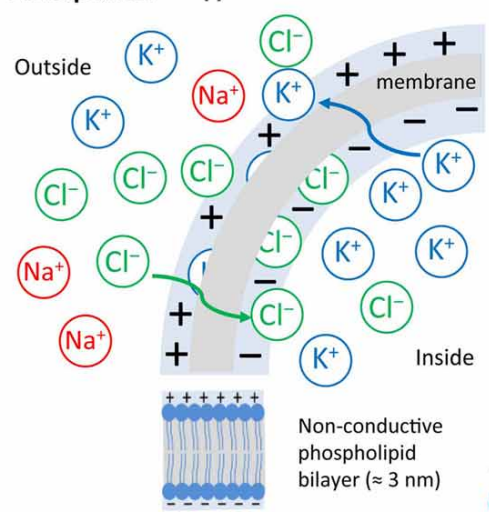

B Structured water

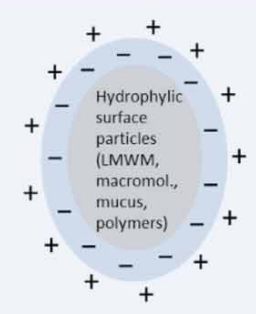

E Biotransistor $=t_{c}^{k}$

(1) Dendrite

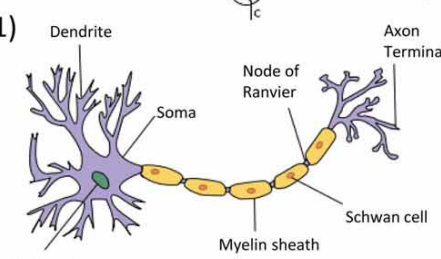

(2)
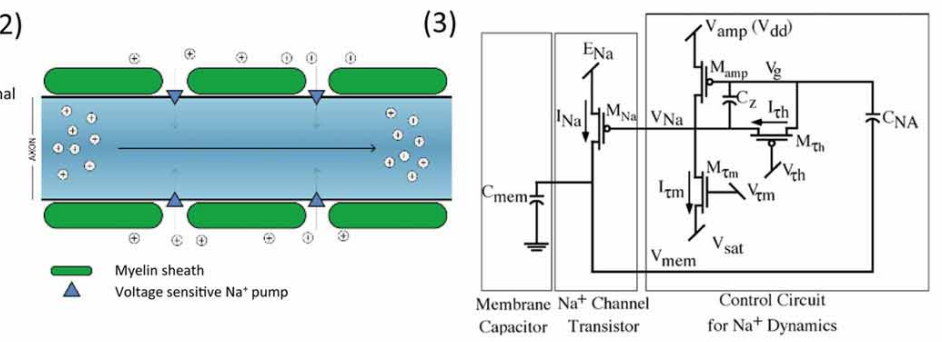

c Biosemiconductor $\longrightarrow$

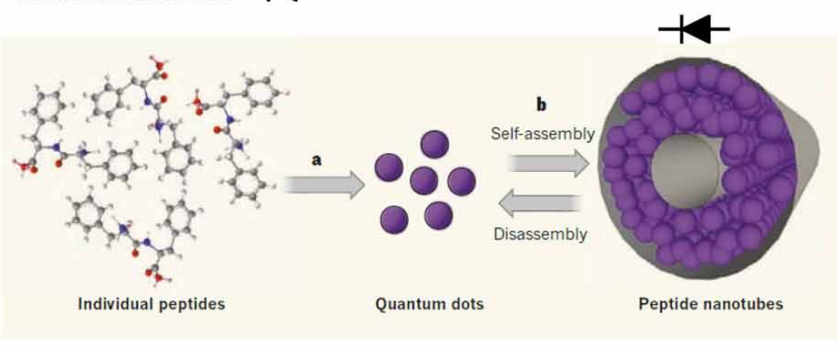

Biodiode $-t y$

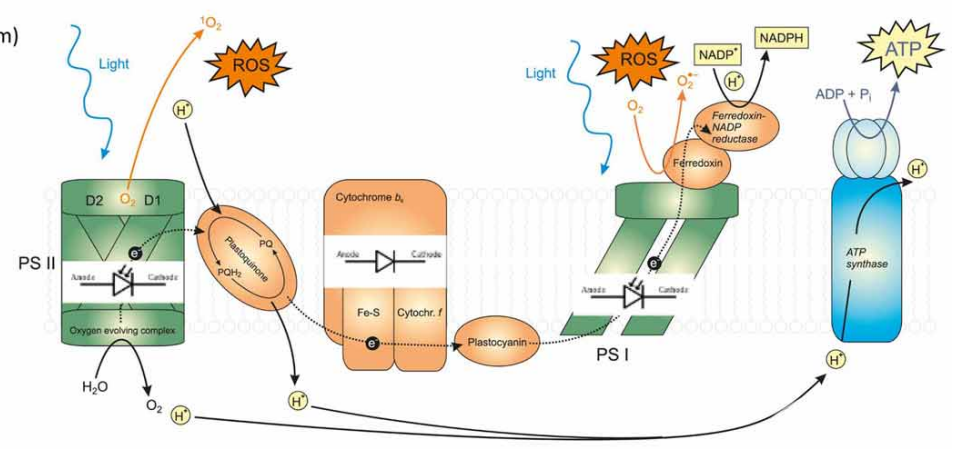

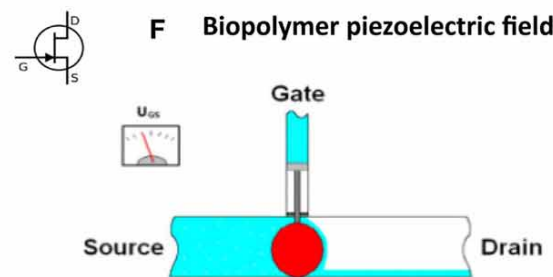

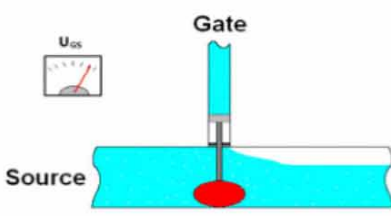

Drain

FIGURE 6 | Bioelectric system components in living organisms. (A) Semipermeable membranes develop a resting potential by selectively allowing diffusion of $\mathrm{K}^{+}$and $\mathrm{Cl}^{-}$until the Coulomb force halts further transfer; (B) particles with hydrophilic surfaces stimulate the development of an exclusion zone with negatively charged more ice-like structured water; (C) peptides can self-assemble into peptide nanotubes with semiconductor properties (Hauser and Zhang, 2010, with permission); (D) protein complexes in photosystem I and II and other protein complexes in the chloroplast can act as light-sensitive and non-light-sensitive diodes during photosynthesis; (E) (1) neurons represent the best explored biotransistors, (2) signaling in the myelin sheath depends on depolarization by $\mathrm{Na}^{+}$influx; (3) the $\mathrm{Na}^{+}$channels are regulated by a system combining a membrane capacitor and a channel transistor (Farquhar and Hasler, 2005, with permission); (F) biopolymer piezoelectric field electron transistor: voltage in biopolymers, such as membranes, cell walls and their associated mucous matrices, can be affected by LMWM chemical activity (for example, increased metal-catalyzed free radical production) in concert with hydrostatic pressure. 
more into the positive (influx of $\mathrm{Na}^{+}$or $\mathrm{Ca}^{+}$), we speak of depolarization, if $\Delta \Psi$ is shifted to a more negative value (efflux of $\mathrm{K}^{+}$ and/or influx of $\mathrm{Cl}^{-}$) of hyperpolarization (Hille, 2001; Carlson, 2014). This potential, again, blocks other similarly charged ions and creates an electrostatic resistance to ion and electron transfer. Thus, although there exist no specific high resistance insulator materials in organisms, substantial electric resistance can form. Consequently, electric charges can arise in many biological compartments. If this happens in a serial cascade, the formed charges may reach a quite substantial amplitude, the most spectacular example being the electric organs of fishes, e.g., those of the electric eel, Electrophorus electricus, with a $\Delta \Psi$ of up to $600 \mathrm{~V}$ (Gotter et al., 1998).

Gerald Pollack proposed that water that is close to hydrophilic structures, resembles more the honeycomb structure of ice with a ratio of hydrogen:water of 2:1 (Figure 6B). Water in this exclusion zone has a negative charge $(-1)$. The adjacent bulk water reacts by forming hydronium ions $\left(\mathrm{H}_{3} \mathrm{O}^{+}\right)$and thus has a positive charge. Charged entities, such as membranes, proteins, and DNA interact and interface with water. The forming $\Delta \Psi$ is theoretically available to drive various cellular processes and would also offer an explanation for the negative potential of the cytosol (Pollack, 2013).

\section{PIEZOELECTRICITY}

Endothermic reactions depend on energy availability. In this context, we should specifically consider biological piezoelectricity. The piezoelectric effect is described as the accumulation of an electrical charge by application of mechanical stress to a crystal (Martin, 1972), but it is known also to occur in certain solid materials of biological origin. Thus, piezoelectricity can cause changes of the membrane potential, the electrostatic fields of the tissue as well as its form (inverse piezoelectric effect). This can happen also in solid biological structures that maintain their specific inner organization and physicochemistry in living tissues. These structures comprise cell walls made of muramic acid, chitin and cellulose, colloidal mucins, phospholipid bilayers in biomembranes, fascia made of collagen, hyaline cartilage and bones (Fukada, 1984; Kim et al., 2010; Cheng and Qian, 2012). Mucus material and plant and bacterial mucilage can form colloid-like matrices on the surface of intra- and extracellular solid structures, thereby acting as interface to various cell- and tissue-specific liquids, such as cytoplasm, lymph and blood. Likewise, depending on water availability, organs are covered by mucus layers of variable depth, which can lubricate the surface, maintain the functional hydration state, and protect against invading microbes (Leppard, 1995; Boyton, 2002; Evert et al., 2009).

\section{METAL-ORGANIC FRAMEWORKS (MOFs)}

The generally accepted notion is that proteins with their surfaces determine the milieu for the majority of chemical reactions. This somehow obscures the fact that LMWMs can form complex ions with a wide range of metals (see Section Bioinorganic or Coordination Chemistry of LMWM), which enables them more or less to act as comparable catalysts to enzymes in terms of potential chemical reactions catalysis though but less on terms of efficiency. A general idea how this can work is illustrated by one of the most-exciting, high profile developments in nanotechnology. Metal-organic frameworks (MOFs) are porous coordination polymers of mucus-like nature that contain metal-containing nodes and organic linker molecules. They are developed currently to serve as drug carriers in form of nanoencapsulators (McKinlay et al., 2010). Owing to their structural regularity and synthetic tunability, considerable hopes are directed at MOFs as platform to hierarchically organize synthetic light-harvesting antennae and catalytic centers to achieve solar energy conversion similarly as in photosynthesis (Zhang and Lin, 2014). Conversely, chloroplastic chlorophyll stacks somehow may be viewed as BioMOFs. LMWM can structure such BioMOFs as organic linker molecules and specifically affect chemical cell processes by regulating substrate availability and catalysis, comparably to and in concert with proteins. Both proteins and BioMOFs cannot avoid being affected by piezoelectric effects.

\section{BIOELECTRIC SYSTEM COMPONENTS}

Some cell structures show striking similarities to basic electronic components (Figure 6). Some examples are presented in the ongoing text.

\section{Biocapacitors}

A capacitor (originally known as a condenser) is a passive twoterminal electrical component used to store energy electrostatically in an electric field (Dorf and Svoboda, 2001). Traditional paper capacitors consist of cellulose layers positioned around a dielectricum in order to store a defined amount of electric charge to facilitate smooth power supply conditioning. A similar structure is found in the intermembraneous space of phospholipid bilayer membranes that surround cell nuclei, chloroplasts, mitochondria and between the cellulose fiber layers of plant cell walls (Figure 6A). Biomembranes show the unique feature of displaying phase transitions (melting) in a physiologically relevant regime (Heimburg, 2012).

\section{Biosemiconductors}

A semiconductor is a material which possesses electrical conductivity between that of a conductor, for example any metal, and that of an insulator, such as glass or silicon. The conductivity of a semiconductor is augmented by "doping." Doping consists of the addition of electron donators to the insulator. In case of silicon, most commonly coordination complex formation with transition metals of the groups III and V is used. In contrast to metals, the conductivity of semiconductors increases with elevated temperature, and also with increased photon radiation (photovoltaic effect). Mucous colloids with complexed metals or hyaline cartilage can possess semiconductor properties (Sze, 1981). Recently, nanotechnology research revealed that peptides can self-assemble into peptide nanotubes by a mechanism that is not yet understood fully. These peptide nanotubes can be components of metallic/semiconductor-organic frameworks (BioMOFs) (Figure 6C) (Amdursky et al., 2010). Consequently, we may assume that peptides can form biosemiconductors in vivo too.

\section{Biodiodes and biotransistors}

A diode is a serial combination of a doped ( $\mathrm{n}$ ) and an unchanged (p) semiconductor. An applied potential may only result in a 
current flow if the cathode is placed at the doped part of the diode. Diodes consisting of semiconductors are also sensitive to light by increasing their conductivity, and may emit light when high potentials are applied (light emitting diode, LED). The photosystems in photoautotrophic organisms can be seen as an array of biodiodes (Figure 6D).

Transistors are serial combinations of three doped and/or unchanged semiconductor elements (npn, pnp). The complete combination is rendered electrically conductive by applying a potential, placing the cathode at the doped element. The base current is applied at the first (emitter) and the middle (base) part. If this is high enough, conductivity between the first (emitter) and the third part (collector) is established. Thus, in essence a transistor represents an electronic switch depending on charge thresholds.

In biosensor development, different types of biologically sensitive field-effect transistors (BioFET) exist, in which whole cells are used to detect changes in extracellular $\mathrm{pH}$, ion concentration, $\mathrm{CO}_{2}$ production, redox potential and metabolic products such as glucose and lactic acid. A special development represents the "beetle/chip" FET that is used to analyze pheromone perception of insects in electroantennogram studies (Schöning and Poghossian, 2002). The physical principles governing ion flow in neurons resemble electron flow through a metal-oxidesemiconductor field-effect transistors (MOSFET) (Figure 6E) (Farquhar and Hasler, 2005).

Apart from neurons, bioelectrical transistor elements have not been investigated intensively so far. The following scenario, however, is feasible: Biopolymer compression (mechanical stress) and/or oxidative (chemical stress) can increase electron availability by piezoelectricity. Mucoproteids with metall-LMWM complexes, especially of iron and copper, can serve as electron accepting "doping" agents. Transition metal-catalyzed electron transfers to molecular oxygen can increase free radicals and other reactive species (Section Oxygen and Other Reactive Species and Bioinorganic or Coordination Chemistry of LMWM). The cytosol is rich in various solutes. Oxidative stress increases LMWM amounts as it triggers antioxidant defenses. As argued by the structured water hypothesis (Ling, 2001; Voeikov, 2001, 2006; Pollack, 2013), structured water zones on hydrophilic and charged surfaces can increase reaction rates of this chemistry by providing more energy due to their battery-like nature and affect the conductivity of a particular tissue region by modulation of the electromagnetic fields in the present biopolymers, such as membrane lipids, cellulose, chitin or collagen and their associated mucous matrices. LMWMs interact with concentrations of reactive species because of their redox chemical properties and affect a multitude of reaction cascades that contribute to the phenomenon of oxidative stress. Such an effect on voltage-sensitive $\mathrm{K}^{+}$channels is documented and accepted as given in a recent critical review (Sahoo et al., 2014), irrespective of any contributions of structured water to this effect and despite the experimental difficulties. Numerous studies document LMWM effects on various membranous ion channels, amongst others by phenols (Ishimaru et al., 2012), peptides (Maischak et al., 2010), and terpenoid LMWMs (Marrè, 1979; Zimmermann and Mithöfer, 2013). Electrical signals can trigger the same downstream responses as chemical ones, only faster. This has been impressively demonstrated for the wound-induced methyl jasmonate-systemin signal cascade, in which an electrical longdistance signal, probably a system potential (see for more details Section Bioelectric Studies) leads to proteinase inhibitor accumulation as systemic response in damaged tomato plants (Wildon et al., 1992). A substantial component of this signal cascade represent changes in xylem hydrostatic pressure (Farmer et al., 2014). Consequently, the scenario of a "biopolymer piezoelectric field electron transistor (BIOPFET)" as suggested by Figure $6 \mathrm{~F}$ is quite feasible despite of the fact that many details request further exploration and clarification.

\section{BIOELECTRIC STUDIES}

Searching the literature for the term "bioelectricity" yields a lot of papers about bioenergy but fewer on physiology. The most cited one dealing with the bioelectricity is a more or less 10 year old review that attempts to clarify several misconceptions that have arisen in connection with physiological bioelectricity (McCaig et al., 2005). The most promising application is the clinical potential of electric field treatment of damaged tissues of epithelia and the nervous system. An important insight from animal studies was that electrical fields exist intra- and extracellularly: (I) Voltage gradients exist within the extracellular spaces underneath the frog skin; (II) disruption of the natural electric fields in amphibians disrupts development; (III) endogenous currents and voltage gradients are present in chick embryos, disrupting them also disrupts development; and (IV) a voltage gradient exists across the neural tube; neuroblasts, the precursor cells of neurons, differentiate in this gradient. Another important insight concerned electrical fields that are generated by healing epithelia, which control the healing process: (I) Rat cornea wound healing is controlled by an electrical field and, specifically-LMWM drugs were shown to affect the cornea's $\Delta \Psi$ (Song et al., 2002); (II) epithelial cell proliferation and the cell division axis are regulated by a physiological electrical field; (III) and nerve growth is regulated by an electrical field. Transcellular signals can regulate the spatial expression of genes that control left/right organ symmetry (Levin et al., 2002). Furthermore, supporting data emerged for the notion that intracellular gradients of potential segregate charged proteins within the cytoplasm, a kind of electrophoresis along cell membranes (Jaffe, 1977).

A genetic study on the role of $G$ protein-coupled receptor signaling in originally as chemotactic identified aggregation of the model slime mold Dictyostelium discoideum suggested that chemo- and electrotaxis share a similar signaling mechanism (Zhao et al., 2002). However, later studies confirmed this only for the most downstream elements (McCaig et al., 2005). Given the high parallels of electro- and chemotactical phenomena, the lack of shared recognition mechanisms still remains enigmatic.

Whereas in animals only one genuine electrical signal is recognized, the action potential, in plants two more can be found, the variation and system potential (Zimmermann and Mithöfer, 2013). The action potential results from a transient depolarization from the plasma membrane (Davies, 1987). Within plants, they are especially evident in those with rapid (nyctinastic) leaf movement, the best known being touch-me-not (Mimosa pudica) 
(Volkov et al., 2010) and the Venus flytrap (Dionaea muscipula) (Volkov et al., 2008).

Variation potentials, sometimes also known as low-wave potentials, represent transient depolarizations of the plasma membrane with variable shape, amplitude and time frame with downstream effects on gene expression (Davies, 1993). They can be elicited by diverse mechanical and physical stimuli, such as heat, wounding, pressure, but also by chemical factors.

Systems potentials, by contrast, reflect a systemic selfpropagating hyperpolarization of the plasma membrane or depolarization of the voltage of the apoplastic colloidal matrix (Zimmermann et al., 2009). The participation of proton pumps in generating these potentials is suggested by triggering activity via the terpenoid LMWM fusicoccin, a toxin of the phytopathogenic fungus Fusicoccum amygdali (Marrè, 1979).

Apart from rapid leaf movement, electrical signals have been shown to be involved in plant root-to-shoot communication, fertilization, photosynthesis regulation, gene expression, longdistance signaling in woody plants, and root growth coordination (Fromm and Lautner, 2012). Moreover, experimental evidence documents that action and variation potentials can affect light and dark reactions of photosynthesis as well as respiration in above- and belowground organs (Pavlovič, 2012). Sessile plants never have developed the same degree of neuronal network complexity as scavenging animals even though electricity also constitutes an important component of their signaling that enables them to survive in changing environments. Long-distance signaling suggests the existence of biocircuits, in plants these might be xylem and phloem vascular bundles, in animals connective tissues (fascia), the latter showing functional conformity with the meridians in Traditional Chinese Medicine (Keown, 2014).

\section{OUTLOOK: LMWMS IN CHEMICAL SYSTEMS REGULATED BY ELECTRICITY}

Systems, biological and chemical, represent huge crossword puzzles waiting to be resolved and there probably exists only one possible solution that facilitates understanding, a simple unifying concept. Today, discipline fragmentation contributes a lot to impeding us finding it (Ling, 2001; Firn, 2010). Such a possible unifying concept could look like the following one:

The Russian cell physiologist Dimitrii Nasonov described the fundamental phenomenon of the universal cell response, UCR, a biphasic response, resting or activated, to external stimuli (stress). The two states differ in terms of protein structure folding (Nasonov, 1962; Ling, 2001; Matveev, 2010). The resting state is a coherent meta-stable low entropy state with water and $\mathrm{K}^{+}$bound to proteins and the active state a higher-entropy state because water and $\mathrm{K}^{+}$are free (Jaeken and Matveev, 2012). The thoughtful reader will now argue that the described cytosolic scenarios contradict the generally favored membrane pump hypothesis (Figure 6A). This is true. But in an attempt to provide a synthesis for all the focused chemical detail mechanisms in terms of a chemical system, we have to adopt a view that considers the phenomenon of cooperativeness as a major component of this chemical system. In biological terminology, cooperativeness could be called symbiosis. Consequently, a focus on membrane potentials is perhaps too reductionist.
The second important phenomenon that is inherent to life is replicative chemistry because it facilitates the required organization for the concomitantly running chemical reactions. If an organism loses that, it's unorganized decomposition starts and the chemistry that accompanies the development of diseases resembles that of organic matter decomposition which exactly follows the second law of thermodynamics by increasing the entropy of the involved systems. In his booklet "What is Life," Erwin Schrödinger stated that life feeds on negative entropy (Schrödinger, 1944), or better Gibbs free energy. Coupling energy input from sunlight and exothermic reactions with endergonic reactions that are not entropically favored defines metabolism in living cells.

The requirements for life chemistry have never been summarized more aptly as by the organic chemist Addy Pross: "a self-sustaining kinetically stable dynamic reaction network derived from replication reaction" (Pross, 2012). In his tantalizing book, though, Addy Pross does not offer examples for the chemical reaction network apart from template availability facilitating nucleotide replication as example for autocatalysis. In attempts to find an approach to deal with LMWM chemical complexity, another author merits mentioning, Bruce B. Jarvis. He regards LMWM as molecular communities that self-assemble into structures that can support complexity when a series of interconnected events occur (Jarvis and Miller, 1996). These complexity events "are characterized by participation in complex interlocked cycles involving feedback mechanisms controlled by an elaborate chemical signaling system, a unicellular organismlife." Unicellular organisms develop into multicellular, the latter organize themselves in communities, and these yield societies.

At this point we want to look at the signaling system in particular and question the statement that a chemical reaction system can be controlled by chemicals. What do chemical reactions require? Electrons and energy. Both is provided by electricity, fast, and universal. Microorganisms can directly accept electrons from electrodes to reduce carbon dioxide, nitrate, metals, organic acids, protons and oxygen (Lovley, 2011). The bacterium Geobacter sulfurreducens masters long-range electrons transport along its pili, so-called microbial nanowires that have the same metallike conductivity as synthetic conducting polymers. Pili networks facilitate biofilm conductivity with supercapacitor and transistor properties (Lovley, 2012). Similarly, proteins and membranes of cellular organelles also represent biotransistors (Figure 7A). Both are biopolymers and are doped with oxygen, nitrogen and sulfur functions that can act as electron donors or acceptors or facilitate metal complexation. In membranes, the lipid bilayer acts as insulator but the glycerol esters, sphingolipid and ceramide functions, for example, can contribute to semiconductor properties. LMWMs can form various non-covalent bonds, charge-transfer or coordination complexes, which contribute to the formation of gel-like biopolymers. Similarly to proteins, these gel biopolymers can contain coordination complexes with metals that can act as catalysts of acid-base or electron transfers. Depending on the oxidation/reduction state of contacting functional groups and the electrical field of the biopolymer complex, electrons and energy are either transferred from or to the protein. As a component of a chemoelectrical signaling system (CSS) biotransistors can act 



FIGURE 7 | A chemoelectrical signaling system (CSS) allows conversion of chemical into electrical information that again can act as feedback loop on the chemical reactions. (A) "Short-range CSS": LMWMs are organized as metal complexes, non-covalent charge-transfer bonding can also structure the complexes that contribute to the gel-like state of the cytosol; these complexes can act as semiconductors together with membranes and proteins; together they act as a biotransistor in the CS. (B) "Long-range CSS":
The occurring chemical reactions cause emission of photons in low concentrations that are still detectable by aromatic structures in remote LMWMs and proteins as feedback mechanism. Covalent bonds are marked in full lines, non-covalent bonds in dotted lines; (A) electron acceptors, (D) electron donors in charge-transfer complexes; electric extension cord symbols indicate $\pi$-electron systems with potential to develop weak localized electromagnetic fields. as a local short-distance signaling mechanism. Structured surface water most likely enhances than impedes its functioning. In colloidal matrix organized LMWMs somehow represent "small coins" that an organism is in constant need of in order to maintain its homeodynamics in a changing environment (Kinzel, 1989).

Ultraweak photon emission denotes the low-intensity spontaneous or inducible photon emission that accompanies chemical reactions (electron transfers). It is emitted both by abiotic matter and living cells and tissues, whole organs and organisms. Research on it was mainly carried out in Eastern Europe, but it is known to increase in response to oxidative stress and thought to originate from ${ }^{1} \mathrm{O}_{2}$, triplet excited states (e.g., carbonyls), peroxynitrite reactions, lipoxygenase activity, haem protein/peroxide reactions and Fenton chemistry, the transition metal catalyzed reduction of $\mathrm{H}_{2} \mathrm{O}_{2}$ to ${ }^{\bullet} \mathrm{OH}$ (Halliwell and Gutteridge, 2007), as well as in structured water zones close to LMWMs, proteins and other hydrophilic surfaces (Voeikov, 2001, 2006) (Figure 5). Vladimir Voeikov suggests that it can be absorbed by aromatic structures that represent a common element in many LMWMs and nucleobases. This property can enable ultraweak photon emission to act as long distance feedback component in the CSS (Figure 7B). 
This herein proposed concept of a chemoelectrical signaling system (CSS) (Figures 7A,B) could serve as a candidate for the self-sustaining kinetically stable dynamic reaction network derived from replication reaction that represents the systems chemistry of a living organisms (Pross, 2012). It also has the potential to regulate its replication by affecting known and hitherto unknown epigenetic control mechanisms of gene expression (Shapiro, 2011). Changes in electrical field intensity and frequency in connected biotransistors could characterize the resting and the active cell state. The CSS can monitor and coordinate the many physiotypes or better physiolomes that cells, tissues and organisms can develop. It provides a concept that can be useful in tackling many still idiosyncratic and enigmatic phenomena in biological sciences. Most of all, it reminds us that we should not loose ourselves in LMWM structural diversity but focus on how the LMWMs cooperate within the CSS they are a part of. Otherwise, we risk not recognizing the forest behind the trees. In the opinion of the authors there exists sufficient compelling evidence for the existence of a CSS in the literature. Last but not least, our conclusions have been already voiced by Albert Szent-Györgyi (Szent-Györgyi, 1960, 1968) and thus are not new. Furthermore, they are aimed at complementing but not at challenging approved paradigms.

\section{ACKNOWLEDGMENTS}

We apologize to all authors whose work we could not cite appropriately due to space restrictions. The authors are grateful for constructive comments from three anonymous reviewers. Furthermore, the authors acknowledge the coverage of the publication fee by the Publikationsfonds 2014/2015 of the GeorgAugust Universität Göttingen.

\section{REFERENCES}

Amdursky, N., Molotskii, M., Gazit, E., and Rosenman, G. (2010). Elementary building blocks of self-assembled peptide nanotubes. J. Am. Chem. Soc. 132, 15632-15636. doi: 10.1021/ja104373e

Anarat-Cappillino, G., and Sattely, E. S. (2014). The chemical logic of plant natural product biosynthesis. Curr. Opin. Plant Biol. 19, 51-58. doi: 10.1016/j.pbi.2014.03.007

Apel, K., and Hirt, H. (2004). Reactive oxygen species: metabolism, oxidative stress, and signal transduction. Annu. Rev. Plant Biol. 55, 373-399. doi: 10.1146/annurev.arplant.55.031903.141701

Asensi-Fabado, M. A., and Munné-Bosch, S. (2010). Vitamins in plants: occurrence, biosynthesis and antioxidant function. Trends Plant Sci. 15, 582-592. doi: 10.1016/j.tplants.2010.07.003

Astier, J., Kulik, A., Koen, E., Besson-Bard, A., Bourque, S., Jeandroz, S., et al. (2012). Protein S-nitrosylation: what's going on in plants? Free Radic. Biol. Med. 53, 1101-1110. doi: 10.1016/j.freeradbiomed.2012.06.032

Ball, P. (2008). Water as an active constituent in cell biology. Chem. Rev. 108, 74-108. doi: 10.1021/cr068037a

Bar-Even, A., Flamholz, A., Noor, E., and Milo, R. (2012). Rethinking glycolysis: on the biochemical logic of metabolic pathways. Nat. Chem. Biol. 8, 509-517. doi: 10.1038/nchembio. 971

Barnes, J., Anderson, L. A., and Phillipson, J. D. (2001). St John's wort (Hypericum perforatum L.): a review of its chemistry, pharmacology and clinical properties. J. Pharm. Pharmacol. 53, 583-600. doi: 10.1211/0022357011775910

Bartoli, C. G., Casalongué, C. A., Simontacchi, M., Marquez-Garcia, B., and Foyer, C. H. (2013). Interactions between hormone and redox signalling pathways in the control of growth and cross tolerance to stress. Environ. Exp. Bot. 94, 73-88. doi: 10.1016/j.envexpbot.2012.05.003

Bednarek, P., and Osbourn, A. (2009). Plant-microbe interactions: chemical diversity in plant defense. Science 324, 746-748. doi: 10.1126/science.1171661
Betina, V. (1989). Mycotoxins. Chemical, Biological, and Environmental Aspects. Amsterdam: Elsevier.

Bleecker, A. B., and Kende, H. (2000). Ethylene: a gaseous signal molecule in plants. Annu. Rev. Cell Dev. Biol. 16, 1-18. doi: 10.1146/annurev.cellbio.16.1.1

Boyton, R. J. (2002). Pulmonary defences to acute respiratory infection. Br. Med. Bull. 61, 1-12. doi: 10.1093/bmb/61.1.1

Bräse, S., Gläser, F., Kramer, C. S., Lindner, S., Linsenmeier, A. M., Masters, K.-S., et al. (2013). The Chemistry of Mycotoxins. New York, NY: Springer.

Buchanan, B. B., Gruissem, W., and Jones, R. L. (eds.). (2009). Biochemistry \& Molecular Biology of Plants. Rockville, MD: American Soc. of Plant Physiologists.

Burns, J., Gardner, P. T., O’Neil, J., Crawford, S., Morecroft, I., McPhail, D. B., et al. (2000). Relationship among antioxidant activity, vasodilation capacity, and phenolic content of red wines. J. Agric. Food Chem. 48, 220-230. doi: 10.1021/jf9909757

Cabello-Hurtado, F., Gicquel, M., and Esnault, M.-A. (2012). Evaluation of the antioxidant potential of cauliflower (Brassica oleracea) from a glucosinolate content perspective. Food Chem. 132, 1003-1009. doi: 10.1016/j.foodchem.2011.11.086

Calabrese, E. J. (2005). Paradigm lost, paradigm found. The re-emergence of hormesis as a fundamental dose response model in the toxicological sciences. Environ. Pollut. 138, 378-411. doi: 10.1016/j.envpol.2004.10.001

Carlson, N. R. (2014). Physiology of Behavior. Harlow: Pearson Ecucation, Inc.

Cheng, Q., and Qian, M.-L. (2012). Piezoelectric effect of cell's membrane. J. Acoust. Soc. Am. 131, 3246. doi: 10.1121/1.4708114

Chobot, V., and Hadacek, F. (2009). Milieu-dependent pro- and antioxidant activity of juglone may explain linear and nonlinear effects on seedling development. J. Chem. Ecol. 35, 383-390. doi: 10.1007/s10886-009-9609-5

Christensen, L. P., and Brandt, K. (2006). Bioactive polyacetylenes in food plants of the apiaceae family: occurrence, bioactivity and analysis. J. Pharm. Biomed. Anal. 41, 683-693. doi: 10.1016/j.jpba.2006.01.057

Clouse, S. D., and Sasse, J. M. (1998). Brassinosteroids: essential regulators of plant growth and development. Annu. Rev. Plant Physiol. Plant Mol. Biol. 49, 427-451. doi: 10.1146/annurev.arplant.49.1.427

Crichton, C. R. (2008). Biological Inorganic Chemistry-An Introduction. Amsterdam: Elsevier.

Crozier, A. (ed.). (2006). Plant Secondary Metabolites: Occurence, Structure and Role in the Human Diet. Oxford: Blackwell Publ.

Curtis, P. J., and Cross, B. E. (1954). Gibberellic acid. A new metabolite from the culture filtrates of Gibberella fujikuroi. Chem. Ind. 35, 1066.

Davies, E. (1987). Action potentials as multifunctional signals in plants-A unifying hypothesis to explain apparently disparate wound responses. Plant Cell Environ. 10, 623-631. doi: 10.1111/j.1365-3040.1987.tb01844.x

Davies, E. (1993). Intercellular and intracellular signals and their transduction via the plasma membrane-cytoskeleton interface. Semin. Cell Biol. 4, 139-147. doi: 10.1006/scel.1993.1017

Davies, K. J. A. (2000). Oxidative stress, antioxidant defenses, and damage removal, repair, and replacement systems. IUBMB Life 50, 279-289. doi: $10.1080 / 15216540051081010$

De Rosa, M., Gambacorta, A., and Gliozzi, A. (1986). Structure, biosynthesis, and physicochemical properties of archaebacterial lipids. Microbiol. Mol. Biol. Rev. 40, 70-80.

De Tullio, M. C. (2010). Antioxidants and redox regulation. Changing notions in a changing world. Plant Physiol. Biochem. 48, 289-291. doi: 10.1016/j.plaphy.2010.02.011

De Tullio, M. C. (2012). Beyond the antioxidant: the double life of vitamin C. Subcell. Biochem. 56, 49-65. doi: 10.1007/978-94-007-2199-9_4

Demain, A. L. (1996). "Fungal secondary metabolim: regulation and function," in A Century of Mycology, ed B. C. Sutton (Cambridge; New York: Cambridge University Press), 233-254.

Demidchik, V. (2015). Mechanisms of oxidative stress in plants: from classical chemistry to cell biology. Environ. Exp. Bot. 109, 212-228. doi: 10.1016/j.envexpbot.2014.06.021

Denisov, E. T., and Denisova, T. G. (2009). The reactivity of natural phenols. Russ. Chem. Rev. 78, 1047-1073. doi: 10.1070/RC2009v078n11ABEH 004084

D'Haeze, W., and Holsters, M. (2002). Nod factor structures, responses, and perception during initiation of nodule development. Glycobiology 12, 79R-105R doi: $10.1093 /$ glycob/12.6.79R 
Diamond, J. M., and Wright, E. M. (1969). Biological membranes: the physical basis of ion and nonelectrolyte selectivity. Annu. Rev. Physiol. 31, 581-646. doi: 10.1146/annurev.ph.31.030169.003053

Dixon, R. A. (2001). Natural products and plant disease resistance. Nature 411, 843-847. doi: $10.1038 / 35081178$

Dorf, R. C., and Svoboda, J. A. (2001). Introduction to Electric Circuits. New York, NY: Wiley.

Doukas, P. H. (1975). "The role of charge-transfer processes in bioactive materials," in Drug Design, ed E. J. Ariëns (New York; London: Academic Press), 133-169.

Eberson, L. E. (1987). Electron Transfer Reactions in Organic Chemistry. Berlin; New York: Springer.

Evert, R. F., Eichhorn, S. E., Langenfeld-Heyser, R., and Esau, K. (2009). Esau's Pflanzenanatomie. Meristeme, Zellen und Gewebe der Pflanzen: Ihre Struktur. Funktion und Entwicklung. Berlin: De Gruyter.

Fani, R., and Fondi, M. (2009). Origin and evolution of metabolic pathways. Phys. Life Rev. 6, 23-52. doi: 10.1016/j.plrev.2008.12.003

Farmer, E. E., Gasperini, D., and Acosta, I. F. (2014). The squeeze cell hypothesis for the activation of jasmonate synthesis in response to wounding. New Phytol. 204, 282-288. doi: 10.1111/nph.12897

Farquhar, E., and Hasler, P. (2005). A bio-physically inspired silicon neuron. IEEE T. Circuits I 52, 477-488. doi: 10.1109/TCSI.2004.842871

Ferrier, D. R., and Harvey, R. A. (2014). Lippincott's Illustrated Reviews: Biochemistry. Philadelphia, PA: Wolters Kluwer Health; Lippincott Williams \& Wilkins.

Firn, R. (2010). Nature's Chemicals. The Natural Products that Shaped Our World. Oxford: Oxford University Press.

Firn, R. D., and Jones, C. G. (2009). A Darwinian view of metabolism: molecular properties determine fitness. J. Exp. Bot. 60, 719-726. doi: 10.1093/jxb/erp002

Fraenkel, G. S. (1959). The raison d'etre of secondary plant substances; these odd chemicals arose as a means of protecting plants from insects and now guide insects to food. Science 129, 1466-1470. doi: 10.1126/science.129.3361.1466

Fraústo da Silva, J. J. R., and Williams, R. J. P. (2001). The Biological Chemistry of the Elements. The Inorganic Chemistry of Life. Oxford, UK: Oxford University Press.

Fridovich, I. (1998). Oxygen toxicity. A radical explanation. J. Exp. Biol. 201, 1203-1209.

Fromm, J., and Lautner, S. (2012). "Generation, transmission, and physiological effects of electrical signals in plants," in Plant Electrophysiology: Signaling and Responses, ed A. G. Volkov (Berlin: Springer), 207-232.

Fujita, M., Fujita, Y., Noutoshi, Y., Takahashi, F., Narusaka, Y., YamaguchiShinozaki, K., et al. (2006). Crosstalk between abiotic and biotic stress responses: a current view from the points of convergence in the stress signaling networks. Curr. Opin. Plant Biol. 9, 436-442. doi: 10.1016/j.pbi.2006.05.014

Fukada, E. (1984). Piezoelectricity of natural biomaterials. Ferroelectrics 60 285-296. doi: 10.1080/00150198408017529

Funk, C. D. (2001). Prostaglandins and leukotrienes: advances in eicosanoid biology. Science 294, 1871-1875. doi: 10.1126/science.294.5548.1871

Fusetani, N. (2012). "Marine natural products," in Natural Products in Chemical Biology, ed N. Civjan (Hoboken, NJ: Wiley), 31-64.

Gershenzon, J. (2002). "Secondary metabolites and plant defense," in Plant Physiology, eds L. Taiz and E. Zeiger (Sunderland, MA: Sinauer), 283-303.

Giles, G. I., and Jacob, C. (2002). Reactive sulfur species. An emerging concept in oxidative stress. Biol. Chem. 383, 375-388. doi: 10.1515/BC.2002.042

Gooday, G. W. (1978). Functions of trisporic acid. Philos. Trans. R. Soc. Lond. B Biol. Sci. 284, 509-520. doi: 10.1098/rstb.1978.0086

Gotter, A. L., Kaetzel, M. A., and Dedman, J. R. (1998). Electrophorus electricus as a model system for the study of membrane excitability. Comp. Biochem. Physiol. A 119, 225-241. doi: 10.1016/S1095-6433(97)00414-5

Gräfe, U. (1992). Biochemie der Antibiotika. Struktur - Biosynthese Wirkmechanismus. Heidelberg: Spektrum Akad. Verlag.

Greenhill, J. V., and Grayshan, P. (1992). "The cevane group of Veratrum alkaloids," in The Alkaloids, eds A. Brossi and G. A. Cordell (San Diego, CA: Academic Press), 177-237.

Greenstein, B., and Wood, D. F. (2011). The Endocrine System at a Glance. Chichester: Wiley-Blackwell.

Groß, F., Durner, J., and Gaupels, F. (2013). Nitric oxide, antioxidants and pro-oxidants in plant defence responses. Front. Plant Sci. 4:419. doi: $10.3389 /$ fpls.2013.00419
Grubb, C. D., and Abel, S. (2006). Glucosinolate metabolism and its control. Trends Plant Sci. 11, 89-100. doi: 10.1016/j.tplants.2005.12.006

Gruhlke, M. C. H., and Slusarenko, A. J. (2012). The biology of reactive sulfur species (RSS). Plant Physiol. Biochem. 59, 98-107. doi 10.1016/j.plaphy.2012.03.016

Gülçın, I., Beydemır, Ş., Alici, H. A., Elmastaş, M., and Büyükokuroğlu, M. E. (2004). In vitro antioxidant properties of morphine. Pharmacol. Res. 49, 59-66. doi: $10.1016 /$ j.phrs.2003.07.012

Hadacek, F. (2002). Secondary metabolites as plant traits: current assessment and future perspectives. Crit. Rev. Plant Sci. 21, 273-322. doi: 10.1080/0735260291044269

Hadacek, F., Engelmeier, D., Bachmann, G., and Chobot, V. (2011). Hormesis and a chemical raison d'ětre for secondary plant metabolites. Dose-Response 9 79-116. doi: 10.2203/dose-response.09-028. Hadacek

Halliwell, B. (2006). Reactive species and antioxidants. Redox biology is a fundamental theme of aerobic life. Plant Physiol. 141, 312-322. doi: 10.1104/pp.106.077073

Halliwell, B., and Gutteridge, J. M. C. (2007). Free Radicals in Biology and Medicine. Oxford: Oxford University Press.

Hardeland, R. (2008). Melatonin, hormone of darkness and more - occurrence, control mechanisms, actions and bioactive metabolites. Cell. Mol. Life Sci. 65, 2001-2018. doi: 10.1007/s00018-008-8001-x

Hartmann, T. (2007). From waste products to ecochemicals. Fifty years research of plant secondary metabolism. Phytochemistry 68, 2831-2846. doi: 10.1016/j.phytochem.2007.09.017

Hauser, C. A. E., and Zhang, S. (2010). Peptides as biological semiconductors Nature 468, 516-517. doi: 10.1038/468516a

Hedden, P., and Thomas, S. (eds.). (2006). Plant Hormone Signaling. Oxford, UK: Blackwell.

Heimburg, T. (2012). The capacitance and electromechanical coupling of lipid membranes close to transitions: the effect of electrostriction. Biophys. J. 103 , 918-929. doi: 10.1016/j.bpj.2012.07.010

Hercules, D. M. (1969). Chemiluminescence from electron-transfer reactions. Acc. Chem. Res. 2, 301-307. doi: 10.1021/ar50022a003

Heyland, A., Hodin, J., and Reitzel, A. M. (2005). Hormone signaling in evolution and development: a non-model system approach. BioEssays $27,64-75$. doi: 10.1002/bies.20136

Hille, B. (2001). Ion Channels of Excitable Membranes. Sunderland, MS: Sinauer. Hiramoto, K., Ojima, N., Sako, K., and Kikugawa, K. (1996). Effect of plant phenolics on the formation of the spin-adduct of hydroxyl radical and the DNA strand breaking by hydroxyl radical. Biol. Pharm. Bull. 19, 558-563. doi: 10.1248/bpb. 19.558

Ishibashi, M., Yamaguchi, N., Sasaki, T., and Kobayashi, J. (1994). Amphidinolide $\mathrm{N}$, a novel 26-membered macrolide with remarkably potent cytotoxicity from the cultured marine dinoflagellate Amphidinium sp. J. Chem. Soc. Chem. Commun. 12, 1455-1456. doi: 10.1039/c39940001455

Ishimaru, Y., Hamamoto, S., Uozumi, N., and Ueda, M. (2012). "Regulatory mechanism of plant nyctinastic movement: an ion channel-related plant behavior," in Plant Electrophysiology: Signaling and Responses, ed A. G. Volkov (Berlin: Springer), 125-142.

Jaeken, L., and Matveev, V. V. (2012). Coherent behavior and the bound state of water and $\mathrm{K}^{+}$imply another model of bioenergetics: negative entropy instead of high-energy bonds. Open Biochem. J. 6, 139-159. doi: $10.2174 / 1874091$ X01206010139

Jaffe, L. F. (1977). Electrophoresis along cell membranes. Nature 265, 600-602. doi: $10.1038 / 265600 \mathrm{a} 0$

Jansen, B. J., and de Groot, A. (2004). Occurrence, biological activity and synthesis of drimane sesquiterpenoids. Nat. Prod. Rep. 21, 449-477. doi: 10.1039/b311170a

Jarvis, B. B., and Miller, J. D. (1996). "Natural products, complexity and evolution," in Phytochemical Diversity and Redundancy in Ecological Interactions, eds J. T. Romeo, J. A. Saunders, and P. Barbosa (New York, NY: Plenum Press), 265-294.

Jerzmanowski, A., and Archacki, R. (2013). "Hormonal signaling in plants and animals: an epigenetic viewpoint," in Epigenetic Memory and Control in Plants, eds G. Grafi and N. Ohad (Berlin, New York: Springer), 107-125.

Jung, I. L., and Kim, I. G. (2003). Thiamine protects against paraquat-induced damage: scavenging activity of reactive oxygen species. Environ. Toxicol. Pharmacol. 15, 19-26. doi: 10.1016/j.etap.2003.08.001 
Kappus, H., and Sies, H. (1981). Toxic drug effects associated with oxygen metabolism: redox cycling and lipid peroxidation. Experientia 37, 1233-1241. doi: 10.1007/BF01948335

Keown, D. (2014). The Spark in the Machine. How the Science of Acupuncture Explains the Mysteries of Western Medicine. London; Philadelphia: Singing Dragon.

Kim, J., Yun, S., Mahadeva, S. K., Yun, K., Yang, S. Y., and Maniruzzaman, M. (2010). Paper actuators made with cellulose and hybrid materials. Sensors 10, 1473-1485. doi: 10.3390/s100301473

Kindermann, M., Stahl, I., Reimold, M., Pankau, W. M., and von Kiedrowski, G. (2005). Systems chemistry. Kinetic and computational analysis of a nearly exponential organic replicator. Angew. Chem. Int. Ed. 44, 6750-6755. doi: 10.1002/anie.200501527

Kinzel, H. (1989). Stoffwechsel der Zelle. Die zentralen Vorgänge des Stoffwechsels mit ihren physikalisch-chemischen Grundlagen. Stuttgart: Ulmer.

Kovacic, P., and Somanathan, R. (2009). Novel, unifying mechanism for mescaline in the central nervous system. Electrochemistry, catechol redox metabolite, receptor, cell signaling and structure activity relationships. Oxid. Med. Cell. Longev. 2, 181-190. doi: 10.4161/oxim.2.4.9380

Langenheim, J. H. (2003). Plant Resins. Chemistry, Evolution, Ecology, and Ethnobotany. Portland, OR: Timber Press.

Leppard, G. G. (1995). The characterization of algal and microbial mucilages and their aggregates in aquatic ecosystems. Sci. Total Environ. 165, 103-131. doi: 10.1016/0048-9697(95)04546-D

Levin, M., Thorlin, T., Robinson, K. R., Nogi, T., and Mercola, M. (2002). Asymmetries in $\mathrm{H}^{+} / \mathrm{K}^{+}$-ATPase and cell membrane potentials comprise a very early step in left-right patterning. Cell 111, 77-89. doi: 10.1016/S00928674(02)00939-X

Ling, G. N. (2001). Life at the Cell and Below-Cell Level. The Hidden History of a Fundamental Revolution in Biology. Melville, NY: Pacific Press.

López-Lara, I. M., and Geiger, O. (2010). "Formation of fatty acids," in Handbook of Hydrocarbon and Lipid Microbiology, ed K. N. Timmis (Berlin: Springer), 385-395.

Lovley, D. R. (2011). Powering microbes with electricity: direct electron transfer from electrodes to microbes. Environ. Microbiol. Rep. 3, 27-35. doi: 10.1111/j.1758-2229.2010.00211.x

Lovley, D. R. (2012). Electromicrobiology. Annu. Rev. Microbiol. 66, 391-409. doi: 10.1146/annurev-micro-092611-150104

Macielag, M. J. (2011). "Chemical properties of antimicrobials and their uniqueness," in Antibiotic Discovery and Development, eds T. J. Dougherty and M. J. Pucci (New York, NY: Springer), 793-820.

Maischak, H., Zimmermann, M. R., Felle, H. H., Boland, W., and Mithöfer, A. (2010). Alamethicin-induced electrical long distance signaling in plants. Plant Signal. Behav. 5, 988-990. doi: 10.4161/psb.5.8.12223

Marrè, E. (1979). Fusicoccin: a tool in plant physiology. Annu. Rev. Plant. Physiol. 30, 273-288. doi: 10.1146/annurev.pp.30.060179.001421

Marschner, P. (ed). (2012). Marschner's Mineral Nutrition of Higher Plants. Amsterdam: Elsevier.

Martin, R. (1972). Piezoelectricity. Phys. Rev. B 5, 1607-1613. doi: 10.1103/PhysRevB.5.1607

Matveev, V. V. (2010). Native aggregation as a cause of origin of temporary cellular structures needed for all forms of cellular activity, signaling and transformations. Theor. Biol. Med. Model. 7:19. doi: 10.1186/1742-4682-7-19

McCaig, C. D., Rajnicek, A. M., Song, B., and Zhao, M. (2005). Controlling cell behavior electrically: current views and future potential. Physiol. Rev. 85, 943-978. doi: 10.1152/physrev.00020.2004

McKinlay, A. C., Morris, R. E., Horcajada, P., Férey, G., Gref, R., Couvreur, P., et al. (2010). BioMOFs: metal-organic frameworks for biological and medical applications. Angew. Chem. Int. Ed. 49, 6260-6266. doi: 10.1002/anie.2010 00048

Mendelsohn, R., and Balick, M. J. (1995). The value of undiscovered pharmaceuticals in tropical forests. Econ. Bot. 49, 223-228. doi: 10.1007/BF02862929

Michal, G. (ed.). (1999). Biochemical Pathways. New York, NY: Wiley.

Mindnich, R., Möller, G., and Adamski, J. (2004). The role of 17 betahydroxysteroid dehydrogenases. Mol. Cell. Endocrinol. 218, 7-20. doi: 10.1016/j.mce.2003.12.006

Modriansky, M., Tyurina, Y. Y., Tyurin, V. A., Matsura, T., Shvedova, A. A. Yalowich, J. C., et al. (2002). Anti-/pro-oxidant effects of phenolic compounds in cells: are colchicine metabolites chain-breaking antioxidants? Toxicology 177, 105-117. doi: 10.1016/S0300-483X(02)00199-3

Møller, I. M., Jensen, P. E., and Hansson, A. (2007). Oxidative modifications to cellular components in plants. Annu. Rev. Plant Biol. 58, 459-481. doi: 10.1146/annurev.arplant.58.032806.103946

Nakagawa, T., Sakurai, T., Nishioka, T., and Touhara, K. (2005). Insect sexpheromone signals mediated by specific combinations of olfactory receptors. Science 307, 1638-1642. doi: 10.1126/science.1106267

Nakamura, H., Kobayashi, J., Ohizumi, Y., and Hirata, Y. (1982). Isolation and structure of aaptamine a novel heteroaromatic substance possessing $\alpha$-blocking activity from the sea sponge Aaptos aaptos. Tetrahedr. Lett. 23, 5555-5558. doi: 10.1016/S0040-4039(00)85893-1

Nasonov, D. N. (1962). Local Reaction of Protoplasm and Gradual Excitation. (Mestnaya Reaktsiya Protoplazmy I Rasprostranyayushcheesya Vozbuzhdenie). Jerusalem: Published for the National Science Foundation, Washington, by the Israel Program for Scientific Translations; (available from the Office of Technical Services, U.S. Dept. of Commerce, Washington).

Niklas, K. J., and Spatz, H.-C. (2012). Plant Physics. Chicago, IL: The University of Chicago Press.

Noble, D. (2006). The Music of Life: Biology Beyond Genes. Oxford, UK: Oxford University Press.

Noor, E., Eden, E., Milo, R., and Alon, U. (2010). Central carbon metabolism as a minimal biochemical walk between precursors for biomass and energy. Mol. Cell 39, 809-820. doi: 10.1016/j.molcel.2010.08.031

Ochiai, E.-I. (2008). Bioorganic Chemistry. A Survey. Amsterdam: Elsevier.

Pavlovič, A. (2012). "The effect of electrical signals on photosynthesis and respiration," in Plant Electrophysiology: Signaling and Responses, ed A. G. Volkov (Berlin: Springer), 33-62.

Pieterse, C. M. J., Leon-Reyes, A., Van der Ent, S., and Van Wees, S. C. M. (2009). Networking by small-molecule hormones in plant immunity. Nat. Chem. Biol. 5, 308-316. doi: 10.1038/nchembio. 164

Pollack, G. H. (2001). Cells, Gels, and the Engines of Life. A New, Unifying Approach to Cell Function. Seattle, WA: Ebner \& Sons.

Pollack, G. H. (2013). The Fourth Phase of Water. Beyond Solid, Liquid, and Vapor. Seattle, WA: Ebner \& Sons.

Preston, R. R., and Wilson, T. E. (2013). Lippincott's Illustrated Reviews. Physiology. Philadelphia; London: Lippincott Williams \& Wilkins.

Pross, A. (1985). The single electron shift as a fundamental process in organic chemistry: the relationship between polar and electron-transfer pathways. Acc. Chem. Res. 18, 212-219. doi: 10.1021/ar00115a004

Pross, A. (1995). Theoretical and Physical Principles of Organic Reactivity. New York, NY: Wiley.

Pross, A. (2005). On the chemical nature and origin of teleonomy. Orig. Life Evol. Biosph. 35, 383-394. doi: 10.1007/s11084-005-2045-9

Pross, A. (2012). What is Life? How Chemistry Becomes Biology. Oxford, UK: Oxford University Press.

Ramel, F., Birtic, S., Cuiné, S., Triantaphylidés, C., Ravanat, J.-L., and Havaux, M. (2012). Chemical quenching of singlet oxygen by carotenoids in plants. Plant Physiol. 158, 1267-1278. doi: 10.1104/pp.111.182394

Reese, R. E., Betts, R. F., and Gumustop, B. (2000). Handbook of Antibiotics. Philadelphia, PA: Lippincott Williams \& Wilkins.

Rohmer, M. (1999). The discovery of a mevalonate-independent pathway for isoprenoid biosynthesis in bacteria, algae and higher plants. Nat. Prod. Rep. 16, 565-574. doi: 10.1039/a709175c

Romeo, J. T., Ibrahim, R., Varin, L., and de Luca, V. (eds.). (2000). Evolution of Metabolic Pathways. Amsterdam; New York: Pergamon.

Rosenthal, G. A. (1982). Plant Nonprotein Amino and Imino Acids. Biological, Biochemical, and Toxicological Properties. New York, NY: Academic Press.

Ruiz-Mirazo, K., Briones, C., and de la Escosura, A. (2014). Prebiotic systems chemistry: new perspectives for the origins of life. Chem. Rev. 114, 285-366. doi: $10.1021 / \mathrm{cr} 2004844$

Sahoo, N., Hoshi, T., and Heinemann, S. H. (2014). Oxidative modulation of voltage-gated potassium channels. Antioxid. Redox Signal. 21, 933-952. doi: 10.1089/ars.2013.5614

Schmid, N. B., Giehl, R. F. H., Döll, S., Mock, H.-P., Strehmel, N., Scheel, D., et al. (2014). Feruloyl-CoA 6'-hydroxylase1-dependent coumarins mediate iron acquisition from alkaline substrates in Arabidopsis. Plant Physiol. 164, 160-172. doi: 10.1104/pp.113.228544 
Schöning, M. J., and Poghossian, A. (2002). Recent advances in biologically sensitive field-effect transistors (BioFETs). Analyst 127, 1137-1151. doi: 10.1039/b204444g

Schrödinger, E. (1944). What is Life? Cambridge, UK: Cambridge University Press. Seigler, D. S. (1998). Plant Secondary Metabolism. London: Chapman \& Hall.

Seybold, S. J., Huber, D. P. W., Lee, J. C., Graves, A. D., and Bohlmann, J. (2006). Pine monoterpenes and pine bark beetles: a marriage of convenience for defense and chemical communication. Phytochem. Rev. 5, 143-178. doi: 10.1007/s11101-006-9002-8

Shahat, A. A., Ibrahim, A. Y., Hendawy, S. F., Omer, E. A., Hammouda, F. M., Abdel-Rahman, F. H., et al. (2011). Chemical composition, antimicrobial and antioxidant activities of essential oils from organically cultivated fennel cultivars. Molecules 16, 1366-1377. doi: 10.3390/molecules 16021366

Shapiro, J. A. (2011). Evolution. A View from the 21st Century. Upper Saddle River, NJ: FT Press Science.

Silverman, R. B. (2002). The Organic Chemistry of Enzyme-Catalyzed Reactions. Amsterdam; Boston: Academic Press.

Smith, E. A., and Macfarlane, G. T. (1996). Enumeration of human colonic bacteria producing phenolic and indolic compounds: effects of $\mathrm{pH}$, carbohydrate availability and retention time on dissimilatory aromatic amino acid metabolism. J. Appl. Bacteriol. 81, 288-302. doi: 10.1111/j.1365-2672.1996.tb04331.x

Song, B., Zhao, M., Forrester, J. V., and McCaig, C. D. (2002). Electrical cues regulate the orientation and frequency of cell division and the rate of wound healing in vivo. Proc. Natl. Acad. Sci. U.S.A. 99, 13577-13582. doi: 10.1073/pnas.202235299

Spindler, K.-D., Hönl, C., Tremmel, C., Braun, S., Ruff, H., and Spindler-Barth, M. (2009). Ecdysteroid hormone action. Cell. Mol. Life Sci. 66, 3837-3850. doi: $10.1007 / \mathrm{s} 00018-009-0112-5$

Srinivasan, K. (2014). Antioxidant potential of spices and their active constituents. Crit. Rev. Food Sci. Nutr. 54, 352-372. doi: 10.1080/10408398.2011. 585525

Sze, S. M. (1981). Physics of Semiconductor Devices. New York, NY: Wiley.

Szent-Györgyi, A. (1957). Bioenergetics. New York, NY: Academic Press.

Szent-Györgyi, A. (1960). Introduction to a Submolecular Biology. New York; London: Academic Press.

Szent-Györgyi, A. (1968). Bioelectrics. New York, NY: Academic Press.

Tarakhovskaya, E. R., Maslov, Y. I., and Shishova, M. F. (2007). Phytohormones in algae. Russ. J. Plant. Physiol. 54, 163-170. doi: 10.1134/S1021443707020021

Tian, B., and Hua, Y. (2005). Concentration-dependence of prooxidant and antioxidant effects of aloin and aloe-emodin on DNA. Food Chem. 91, 413-418. doi: 10.1016/j.foodchem.2004.06.018

Torssell, K. (1993). Natural Product Chemistry. A Mechanistic and Biosynthetic Approach to Secondary Metabolism. Stockholm: Swedisch Pharmaceutical Press.

Triantaphylidès, C., and Havaux, M. (2009). Singlet oxygen in plants: production, detoxification and signaling. Trends Plant Sci. 14, 219-228. doi: 10.1016/j.tplants.2009.01.008

Vestergaard, C. L., Flyvbjerg, H., and Møller, I. M. (2012). Intracellular signaling by diffusion: can waves of hydrogen peroxide transmit intracellular information in plant cells? Front. Plant Sci. 3:295. doi: 10.3389/fpls.2012.00295

Voeikov, V. (2001). Reactive oxygen species, water, photons and life. Biol. Forum 94, 193-214. doi: 10.1400/22857

Voeikov, V. (2006). "Biological significance of active oxygen-dependent processes in aqueous systems," in Water and the Cell, eds G. H. Pollack, I. V. Cameron, and D. N. Wheatly (Dordrecht: Springer), 285-298.

Volkov, A. G., Adesina, T., Markin, V. S., and Jovanov, E. (2008). Kinetics and mechanism of Dionaea muscipula trap closing. Plant Physiol. 146, 694-702. doi: 10.1104/pp.107.108241

Volkov, A. G., Foster, J. C., and Markin, V. S. (2010). Signal transduction in Mimosa pudica: biologically closed electrical circuits. Plant Cell Environ. 33, 816-827. doi: 10.1111/j.1365-3040.2009.02108.x

von Lintig, J. (2012). Metabolism of carotenoids and retinoids related to vision. J. Biol. Chem. 287, 1627-1634. doi: 10.1074/jbc.R111.303990

Waldie, T., McCulloch, H., and Leyser, O. (2014). Strigolactones and the control of plant development: lessons from shoot branching. Plant J. 79, 607-622. doi: $10.1111 /$ tpj. 12488

Wall, M. E., and Wani, M. C. (1995). Camptothecin and taxol: discovery to clinicthirteenth Bruce F. Cain Memorial Award Lecture. Cancer Res. 55, 753-760.
Wang, J., Soisson, S. M., Young, K., Shoop, W., Kodali, S., Galgoci, A., et al. (2006). Platensimycin is a selective FabF inhibitor with potent antibiotic properties. Nature 441, 358-361. doi: 10.1038/nature04784

Watson, J. (2013). Oxidants, antioxidants and the current incurability of metastatic cancers. Open Biol. 3:120144. doi: 10.1098/rsob.120144

Webb, M. E., Marquet, A., Mendel, R. R., Rébeillé, F., and Smith, A. G. (2007). Elucidating biosynthetic pathways for vitamins and cofactors. Nat. Prod. Rep. 24, 988-1008. doi: 10.1039/b703105j

Weng, J.-K., and Noel, J. P. (2012). The remarkable pliability and promiscuity of specialized metabolism. Cold Spring Harb. Symp. Quant. Biol. 77, 309-320. doi: 10.1101/sqb.2012.77.014787

Wildon, D. C., Thain, J. F., Minchin, P. E. H., Gubb, I. R., Reilly, A. J., Skipper, Y. D., et al. (1992). Electrical signalling and systemic proteinase inhibitor induction in the wounded plant. Nature 360, 62-65. doi: 10.1038/360062a0

Williams, D. H., Stone, M. J., Hauck, P. R., and Rahman, S. K. (1989). Why are secondary metabolites (natural products) biosynthesized. J. Nat. Prod. 52, 1189-1208. doi: 10.1021/np50066a001

Williams, R. J. P., and Fraústo da Silva, J. J. R. (2006). The Chemistry of Evolution. The Development of Our Ecosystem. Amsterdam; Boston: Elsevier.

Williams, R. J. P., and Rickaby, R. E. M. (2012). Evolution's Destiny. Co-evolving Chemistry of the Environment and Life. Cambridge, UK: Royal Society of Chemistry.

Wink, M., and Schimmer, O. (2010). "Molecular modes of action of defensive secondary metabolites," in Functions and Biotechnology of Plant Secondary Metabolites, ed M. Wink (Chichester: Wiley-Blackwell), 21-261.

Wink, M., and van Wyk, B.-E. (2008). Mind-Altering and Poisonous Plants of the World. Portland, OR: Timber Press.

Woodward, A. W., and Bartel, B. (2005). Auxin: regulation, action, and interaction. Ann. Bot. 95, 707-735. doi: 10.1093/aob/mci083

Wu, Q.-H., Wang, X., Yang, W., Nuessler, A. K., Xiong, L.-Y., Kuca, K., et al. (2014). Oxidative stress-mediated cytotoxicity and metabolism of T-2 toxin and deoxynivalenol in animals and humans: an update. Arch. Toxicol. 88, 1309-1326. doi: 10.1007/s00204-014-1280-0

Yamanaka, N., Rewitz, K. F., and O'Connor, M. B. (2013). Ecdysone control of developmental transitions: lessons from Drosophila research. Annu. Rev. Entomol. 58, 497-516. doi: 10.1146/annurev-ento-120811-153608

Zhang, T., and Lin, W. (2014). Metal-organic frameworks for artificial photosynthesis and photocatalysis. Chem. Soc. Rev. 43, 5982-5993. doi: 10.1039/C4CS00103F

Zhao, M., Jin, T., McCaig, C. D., Forrester, J. V., and Devreotes, P. N. (2002). Genetic analysis of the role of $\mathrm{G}$ protein-coupled receptor signaling in electrotaxis. J. Cell Biol. 157, 921-927. doi: 10.1083/jcb.200112070

Zimmermann, M. R., Maischak, H., Mithoefer, A., Boland, W., and Felle, H. H. (2009). System potentials, a novel electrical long-distance apoplastic signal in plants, induced by wounding. Plant Physiol. 149, 1593-1600. doi: 10.1104/pp.108.133884

Zimmermann, M. R., and Mithöfer, A. (2013). "Electrical long-distance signalling in plants," in Long-Distance Systemic Signaling and Communication in Plants, ed F. Baluška (Berlin; New York: Springer), 291-308.

Conflict of Interest Statement: The authors declare that the research was conducted in the absence of any commercial or financial relationships that could be construed as a potential conflict of interest.

Received: 30 November 2014; accepted: 11 February 2015; published online: 04 March 2015.

Citation: Hadacek F and Bachmann G (2015) Low-molecular-weight metabolite systems chemistry. Front. Environ. Sci. 3:12. doi: 10.3389/fenvs.2015.00012

This article was submitted to Environmental Toxicology, a section of the journal Frontiers in Environmental Science.

Copyright (c) 2015 Hadacek and Bachmann. This is an open-access article distributed under the terms of the Creative Commons Attribution License (CC BY). The use, distribution or reproduction in other forums is permitted, provided the original author(s) or licensor are credited and that the original publication in this journal is cited, in accordance with accepted academic practice. No use, distribution or reproduction is permitted which does not comply with these terms. 